\title{
The oldest fossil record of bandicoots (Marsupialia; Peramelemorphia) from the late Oligocene of Australia
}

\author{
K.J. Travouillon, R.M.D. Beck, S.J. Hand, and M. Archer
}

\begin{abstract}
Two new late Oligocene representatives of the marsupial order Peramelemorphia (bandicoots and bilbies) from the Etadunna Formation of South Australia are described here. Bulungu muirheadae sp. nov., from Zone B (Ditjimanka Local Fauna [LF]), is represented by several dentaries and isolated upper and lower molars. Bulungu campbelli sp. nov., from Zone C (Ngapakaldi LF), is represented by a single dentary and maxilla. Together, they represent the oldest fossil bandicoots described to date. Both are small (estimated body mass of $<250$ grams) in comparison to most living bandicoot species and were probably insectivorous based on their dental morphology. They appear to be congeneric with Bulungu palara from Miocene local faunas of the Riversleigh World Heritage Area (WHA), Queensland and the Kutjamarpu LF (Wipajiri Formation) of South Australia. However, the Zone B peramelemorphian appears to be more plesiomorphic than $B$. palara in its retention of complete centrocristae on all upper molars.
\end{abstract}

K. J. Travouillon. School of Earth Sciences, University of Queensland, St Lucia, Queensland 4072, Australia kennytravouillon@hotmail.com and School of Biological, Earth and Environmental Sciences, University of New South Wales, New South Wales 2052, Australia

R.M.D. Beck. School of Biological, Earth and Environmental Sciences, University of New South Wales, New South Wales 2052, Australia robin.beck@unsw.edu.au

S.J. Hand. School of Biological, Earth and Environmental Sciences, University of New South Wales, New South Wales 2052, Australia s.hand@unsw.edu.au

M. Archer. School of Biological, Earth and Environmental Sciences, University of New South Wales, New South Wales 2052, Australia m.archer@unsw.edu.au

Keywords: Peramelemorphian; Oligocene; South Australia; bandicoot; new species; marsupials

\section{INTRODUCTION}

The fossil record of bandicoots and bilbies (Marsupialia: Peramelemorphia) remains relatively poorly known, with only 13 species described to date (excluding Quaternary records of extant species) from sites spanning the late Oligocene to Pleistocene. The only extinct species to have been

PE Article Number: 16.2.13A

Copyright: Palaeontological Association May 2013

Submission: 6 November 2012. Acceptance: 30 January 2013

Travouillon, K.J., Beck, R.M.D., Hand, S.J., and Archer M. 2013. The oldest fossil record of bandicoots (Marsupialia; Peramelemorphia) from the late Oligocene of Australia, Palaeontologia Electronica Vol. 16, Issue 2; 13A 52p; palaeo-electronica.org/content/2013/400-late-oligocene-bandicoot 
described from the Pleistocene is Perameles sobbei from the Darling Downs, Queensland (Price, 2002; 2005). Five Pliocene peramelemorphians have been described including Perameles allinghamensis from the Bluff Downs Local Fauna (LF), Queensland (Archer and Wade, 1976), Perameles bowensis from the Bow and Wellington Caves LFs, New South Wales (Muirhead et al., 1997), cf. Peroryctes tedfordi and cf. Peroryctes sp. from the Hamilton LF, Victoria (Turnbull et al., 2003) and Ischnodon australis, from the Palankarinna LF, South Australia (Stirton, 1955). The bizarre, dentally autapomorphic Numbigilga ernielundeliusi from the Bluff Downs LF (Beck et al., 2008a) may represent a sixth Pliocene peramelemorphian species.

Ongoing research on fossil peramelemorphians from late Oligocene and early Miocene sites (Muirhead, 1994, 2000; Muirhead and Filan, 1995; Case, 2001; Schwartz, 2006; Travouillon et al., 2010, 2013; Gurovich et al., 2013), particularly relatively complete specimens from the Riversleigh World Heritage Area (WHA), has led to increasingly detailed knowledge of the evolutionary history of Peramelemorphia during this key period. Six species have been described from the Miocene, namely Yarala burchfieldi (Muirhead and Filan, 1995; Muirhead, 2000), Galadi speciosus (Travouillon et al., 2010), G. adversus, G. grandis, G. amplus (Travouillon et al., 2013) from Riversleigh LFs, and Bulungu palara (Gurovich et al., 2013) from multiple LFs at Riversleigh WHA and the Kutjamarpu LF, South Australia. Yarala kida (Schwartz, 2006) from the late Oligocene or early Miocene Kangaroo Well LF (see Metzger and Retallack, 2010) is currently the oldest described peramelemorphian. However, Woodburne et al. (1993) and Case (2001) reported a number of peramelemorphian species from the Etadunna and Wipajiri Formations of South Australia, some of which may predate the Kangaroo Well LF (see also Woodburne and Case, 1996, 144, 150-151).

Here we describe two new peramelemorphian species from two of the oldest faunal zones of the Etadunna Formation, the Ditjimanka LF (Faunal Zone B) and Ngapakaldi LF (Faunal Zone C). We assess the phylogenetic relationships of these to other peramelemorphians to shed light on the early evolutionary history of the order.

\section{MATERIALS AND METHODS}

\section{Collecting and Processing}

Specimens described here were collected from Tedford Locality (Site 2), site code RV 7230, Lake Palankarinna, Etadunna Formation, Ditjimanka LF, Zone B and Ngapakaldi Quarry, site code $\vee 5858$, Lake Ngapakaldi, Etadunna Formation, Ngapakaldi LF, Zone C, by Stirton, Tedford, Woodburne, Archer and co-workers between 1957 and 1972. All specimens collected after 1970 were recovered by screen-washing in the field (Campbell, 1976).

\section{Anatomical Terminology}

Dental terminology follows Archer (1976), Muirhead and Filan (1995), Travouillon et al. (2010) and Turnbull et al. (2003), with molar loci homology following Luckett (1993). Peramelemorphian systematics follows Muirhead (1994, 2000), Muirhead and Filan (1995) and Travouillon et al. (2010). Higher-level marsupial systematics follow the classification of Aplin and Archer (1987).

\section{Institutional Abbreviations}

QM F Queensland Museum Fossil collection, Brisbane, Australia; SAM P South Australian Museum, Palaeontology Collection, Adelaide, Australia; UCMP University of California, Museum of Paleontology, Berkeley, USA; UCR University of California, Riverside, USA.

\section{Body Mass Estimates}

The maximum length and width of each tooth on each specimen were measured (see Tables 1 and 2). These measurements were used to estimate individual body mass of each specimen, using Myers' (2001) allometric relationships between dental measurements and body mass for predicting marsupial body mass. We used the highest ranked equation from Myers (2001) in the "all species excluding dasyuromorphians" dataset, which is the most suitable dataset for bandicoots. For example, when more than one tooth was present in a specimen, we used the highest ranked equation on the tooth row (e.g., 4LMA > 3LMA > 2LMA > 1LMA). All body mass estimates are shown in grams in Tables 1 and 2. Average body mass for the species was calculated from these estimates.

\section{Phylogenetic Analysis}

Phylogenetic relationships within Peramelemorphia were assessed using a revised ver- 
TABLE 1. Measurements of the upper dentition of type and referred material in $\mathrm{mm}$; body mass estimates in grams. $L-$ anteroposterior length, $\mathrm{W}=$ lingual-buccal width, $\mathrm{M}=$ molar. Measurements of damaged/broken teeth are in brackets.

\begin{tabular}{|c|c|c|c|c|c|c|c|c|c|}
\hline \multirow[b]{2}{*}{ Taxa } & \multirow{2}{*}{ Specimen } & \multirow{2}{*}{ Locality } & \multicolumn{2}{|c|}{ M1 } & \multicolumn{2}{|c|}{ M2 } & \multicolumn{2}{|c|}{ M3 } & \multirow{2}{*}{$\begin{array}{c}\text { Body mass } \\
\text { estimate }\end{array}$} \\
\hline & & & $\mathbf{L}$ & $\mathbf{W}$ & $\mathbf{L}$ & $\mathbf{W}$ & $\mathbf{L}$ & $\mathbf{W}$ & \\
\hline $\begin{array}{l}\text { Bulungu } \\
\text { muirheadae }\end{array}$ & QM F10662 & Tedford Locality & & & & & 2.21 & 2.12 & 211.45 \\
\hline $\begin{array}{l}\text { Bulungu } \\
\text { muirheadae }\end{array}$ & QM F10664 & Tedford Locality & & & 2.22 & 1.57 & & & 129.49 \\
\hline $\begin{array}{l}\text { Bulungu } \\
\text { muirheadae }\end{array}$ & QM F10665 & Tedford Locality & & & & & 1.88 & 1.83 & 131.95 \\
\hline $\begin{array}{l}\text { Bulungu } \\
\text { muirheadae }\end{array}$ & QM F12416 & Tedford Locality & 2.12 & 1.84 & & & & & 171.8 \\
\hline $\begin{array}{l}\text { Bulungu } \\
\text { muirheadae }\end{array}$ & QM F12417 & Tedford Locality & & & & & 2.05 & 1.86 & 154.38 \\
\hline $\begin{array}{l}\text { Bulungu } \\
\text { muirheadae }\end{array}$ & QM F12420 & Tedford Locality & & & 1.88 & 1.47 & & & 90 \\
\hline $\begin{array}{l}\text { Bulungu } \\
\text { muirheadae }\end{array}$ & UCMP 108063 & Tedford Locality & & & & & 2.12 & 1.98 & 178.78 \\
\hline $\begin{array}{l}\text { Bulungu } \\
\text { muirheadae }\end{array}$ & UCR 15270 & Tedford Locality & & & & & 2.08 & 1.7 & 137.59 \\
\hline $\begin{array}{l}\text { Bulungu } \\
\text { muirheadae }\end{array}$ & UCR 15275 & Tedford Locality & & & & & 1.89 & 1.76 & 125.32 \\
\hline $\begin{array}{l}\text { Bulungu } \\
\text { muirheadae }\end{array}$ & UCR 15285 & Tedford Locality & & & & & 2 & 1.75 & 135.45 \\
\hline $\begin{array}{l}\text { Bulungu } \\
\text { muirheadae }\end{array}$ & UCR 15299 & Tedford Locality & & & 1.86 & 1.45 & & & 86.62 \\
\hline $\begin{array}{l}\text { Bulungu } \\
\text { muirheadae }\end{array}$ & UCR 15307 & Tedford Locality & 1.91 & 1.5 & & & & & 106.22 \\
\hline $\begin{array}{l}\text { Bulungu } \\
\text { muirheadae }\end{array}$ & UCR15332 & Tedford Locality & & & $(1.83)$ & 1.57 & & & $\mathrm{n} / \mathrm{a}$ \\
\hline $\begin{array}{l}\text { Bulungu } \\
\text { muirheadae }\end{array}$ & UCR 16996 & Tedford Locality & 1.88 & $(1.24)$ & & & & & $\mathrm{n} / \mathrm{a}$ \\
\hline $\begin{array}{l}\text { Bulungu } \\
\text { campbelli }\end{array}$ & SAM P13853 & Ngapakaldi Quarry & & & & & 1.7 & 1.75 & 105.68 \\
\hline
\end{tabular}

sion of the matrix used by Travouillon et al. (2010), Travouillon et al. (2013), and Gurovich et al. (2013), comprising 156 qualitative morphological characters, of which 123 are dental and 33 cranial (see Appendix 1 and 2). To help resolve relationships among fossil peramelemorphians, most of which are known only from isolated dental remains, we have added 96 new dental and cranial characters relative to previous iterations of this matrix. Some characters from the original matrix were modified by adding, removing, or revising ambiguous character states, and some characters were deleted to be replaced by more comprehensive characters (see Appendix 1). Seventy-one characters represent putative morphocline/transformation series (see Appendix 1) and so were ordered in all analyses. All taxa were rescored for this study, to confirm previous scoring decisions and to correct errors present in previous versions of the matrix (e.g., we revised a number of characters scorings for Ischnodon australis). We used the same ingroup peramelemorphian species used by Travouillon et al. (2013) and Gurovich et al. (2013), except as follows. We deleted Microperoryctes ornata from the matrix because the specimens from the Australian Museum that were previously (ibid) used to score this taxon have subsequently been reassigned by museum staff to Microperoryctes longicauda. We have also scored and added all fossil bandicoots described to date to the matrix (cf. Peroryctes tedfordi, cf. Peroryctes sp., Perameles sobbei, Perameles bowensis, Perameles allinghamensis, Ischnodon australis, Yarala burchfieldi, Yarala kida, Galadi speciosus, Galadi grandis, Galadi amplus, Galadi adversus and Bulungu palara). Numbigilga ernielundeliusi 
TABLE 2. Measurements of the lower dentition of type and referred material in $\mathrm{mms}$; body mass estimates in grams. $\mathrm{L}=$ anteroposterior length, $\mathrm{AW}=$ anterior width, $\mathrm{PW}=$ posterior width, $\mathrm{m}=$ molar.

\begin{tabular}{|c|c|c|c|c|c|c|c|c|c|c|c|}
\hline \multirow{2}{*}{ Taxa } & \multirow{2}{*}{ Specimen } & \multirow{2}{*}{ Locality } & \multicolumn{2}{|c|}{ m1 } & \multicolumn{2}{|c|}{ m2 } & \multicolumn{2}{|c|}{ m3 } & \multicolumn{2}{|c|}{$\mathrm{m} 4$} & \multirow{2}{*}{$\begin{array}{c}\text { Body mass } \\
\text { estimate }\end{array}$} \\
\hline & & & $\mathbf{L}$ & $\mathbf{W}$ & $\mathbf{L}$ & $\mathbf{W}$ & $\mathbf{L}$ & $\mathbf{W}$ & $\mathbf{L}$ & $\mathbf{W}$ & \\
\hline $\begin{array}{l}\text { Bulungu } \\
\text { muirheadae }\end{array}$ & QM F10661 & Tedford Locality & 1.57 & 1.12 & & & & & & & 109.34 \\
\hline $\begin{array}{l}\text { Bulungu } \\
\text { muirheadae }\end{array}$ & QM F10666 & Tedford Locality & 1.71 & 1 & 1.84 & 1.14 & 1.95 & 1.19 & & & 127.57 \\
\hline $\begin{array}{l}\text { Bulungu } \\
\text { muirheadae }\end{array}$ & QM F10667 & Tedford Locality & & & 1.67 & 1.25 & 1.89 & 1.26 & - & 1.02 & 132.31 \\
\hline $\begin{array}{l}\text { Bulungu } \\
\text { muirheadae }\end{array}$ & QM F10668 & Tedford Locality & & & & & & & 2.17 & 1.17 & 186.66 \\
\hline $\begin{array}{l}\text { Bulungu } \\
\text { muirheadae }\end{array}$ & QM F10669 & Tedford Locality & 1.7 & 1.09 & 1.76 & 1.24 & & & & & 118.22 \\
\hline $\begin{array}{l}\text { Bulungu } \\
\text { muirheadae }\end{array}$ & QM F12414 & Tedford Locality & & & & & 1.9 & 1.23 & & & 128.85 \\
\hline $\begin{array}{l}\text { Bulungu } \\
\text { muirheadae }\end{array}$ & QM F12415 & Tedford Locality & & & & & 2.17 & 1.38 & & & 182.68 \\
\hline $\begin{array}{l}\text { Bulungu } \\
\text { muirheadae }\end{array}$ & QM F12418 & Tedford Locality & & & & & 2.1 & 1.28 & & & 156.9 \\
\hline $\begin{array}{l}\text { Bulungu } \\
\text { muirheadae }\end{array}$ & QM F12419 & Tedford Locality & 1.73 & 1.15 & & & & & & & 124.59 \\
\hline $\begin{array}{l}\text { Bulungu } \\
\text { muirheadae }\end{array}$ & UCR 15266 & Tedford Locality & & & & & & & 2 & 1.03 & 142.1 \\
\hline $\begin{array}{l}\text { Bulungu } \\
\text { muirheadae }\end{array}$ & UCR 15268 & Tedford Locality & 1.91 & 1.17 & & & & & & & 147.14 \\
\hline $\begin{array}{l}\text { Bulungu } \\
\text { muirheadae }\end{array}$ & UCR 15279 & Tedford Locality & & & 1.79 & 1.12 & & & & & 104.66 \\
\hline $\begin{array}{l}\text { Bulungu } \\
\text { muirheadae }\end{array}$ & UCR 15301 & Tedford Locality & & & 1.76 & 1.18 & & & & & 110.1 \\
\hline $\begin{array}{l}\text { Bulungu } \\
\text { muirheadae }\end{array}$ & UCR 15306 & Tedford Locality & & & & & 1.89 & 1.21 & & & 124.97 \\
\hline $\begin{array}{l}\text { Bulungu } \\
\text { muirheadae }\end{array}$ & UCR 15318 & Tedford Locality & & & 1.78 & 1.24 & & & & & 120.16 \\
\hline $\begin{array}{l}\text { Bulungu } \\
\text { muirheadae }\end{array}$ & UCR 17002 & Tedford Locality & & & & & 2.2 & 1.5 & & & 209.44 \\
\hline $\begin{array}{l}\text { Bulungu } \\
\text { campbelli }\end{array}$ & SAMP 13853 & $\begin{array}{c}\text { Ngapakaldi } \\
\text { Quarry }\end{array}$ & & & 1.79 & 1.11 & 1.75 & 1.32 & 1.79 & 1.09 & 132.38 \\
\hline $\begin{array}{l}\text { Bulungu } \\
\text { campbelli }\end{array}$ & SAMP 13853 & $\begin{array}{c}\text { Ngapakaldi } \\
\text { Quarry }\end{array}$ & 1.55 & 1.07 & & & & & & & 100.56 \\
\hline
\end{tabular}

has not been included, due to its highly autapomorphic dental morphology and questionable peramelemorphian affinities. In addition to the outgroup taxa used by Travouillon et al. (2013) and Gurovich et al. (2013) - namely the fossil dasyuromorphians Barinya wangala and Mutpuracinus archibaldi and the early Eocene stem-australidelphan Djarthia murgonensis, we also scored five new extant outgroup species from the family Dasyuridae: the dasyurines Dasyurus hallucatus, Dasyuroides byrnei, Phascogale tapoatafa and
Antechinus stuartii, and the sminthopsine Sminthopsis macroura.

\section{Unconstrained Maximum Parsimony Analysis}

Unconstrained maximum parsimony analysis of the matrix was performed using PAUP* $4.0 \mathrm{~b} 10$ (Swofford, 2002). Following Worthy et al. (2006) and Beck et al. (2008b), a two-stage search strategy was used with an initial search comprising 1,000 heuristic replicates, saving 10 trees per replicate, followed by a second heuristic search within 
these saved trees. The multiple most parsimonious trees produced were summarised using strict consensus. Bootstrap values for each node in the strict consensus were calculated using 1000 bootstrap replicates, each of which itself comprises 10 random addition replicates. Decay indices were also calculated using AutoDecay 5.0 (Eriksson, 2001) in combination with the perl script perIRat, which implements the parsimony ratchet; the default settings for perlRat (five batches of 200 replicates, randomly upweighting $25 \%$ of characters by a factor of two) were used to implement parsimony ratchet searches to calculate decay indices for all nodes in the strict consensus.

\section{Molecular Scaffold Parsimony Analysis}

For this analysis, the matrix was analysed using the same methods as for the unconstrained maximum parsimony analysis, but with a "molecular scaffold" as a "backbone" constraint. For the molecular scaffold, relationships among extant peramelemorphians were constrained to match the recent molecular phylogeny of Westerman et al. (2012); only those peramelemorphian taxa analysed by Westerman et al. (2012) were included in the molecular scaffold, and only those clades that received $\geq 70 \%$ partitioned maximum likelihood bootstrap support and $\geq 0.95$ partitioned Bayesian posterior probability in the analyses of Westerman et al. (2012, table 2) were enforced as monophyletic. The five extant dasyurid outgroup taxa were also included in the molecular scaffold, with their relationships constrained to match those recovered by Krajewski et al. (2007, figure 5) and Westerman et al. (2008, figure 2). As in the unconstrained maximum parsimony analysis, bootstrap support values were calculated for all nodes present in the strict consensus of most parsimonious trees and using 1000 bootstrap replicates of 10 random addition sequence replicates each, but enforcing the molecular scaffold. The molecular scaffold topology is included in the supplementary information accompanying this paper (Appendix 3).

\section{Unconstrained Bayesian Analysis}

Bayesian analysis of the matrix using the Lewis (2001) "Mk" model for discrete morphological characters was implemented with MrBayes 3.2. Because the matrix included autapomorphies, the analysis assumed that variable (rather than purely parsimony-informative) characters were scored ("coding=var"). The analysis was run for 5 million generations but with otherwise default settings. The first 1.25 million generations (i.e., 25\%) were discarded as burn-in. The potential scale reduction factor (PSRF) and minimum and average effective sample sizes (ESS) for both the tree length and alpha parameters were 1.0 and $>5000$, respectively, for the post-burn-in trees, indicating that stationarity and convergence had been achieved. The post-burn-in trees were summarised using 50\% majority rule consensus, with Bayesian posterior probabilities as support values.

\section{Molecular Scaffold Bayesian Analysis}

The Bayesian analysis was repeated enforcing the same molecular scaffold as for the molecular scaffold parsimony analysis. The molecular scaffold was implemented using multiple "partial" constraints, with each constraint corresponding to a node in the molecular scaffold. All other settings were the same as for the unconstrained Bayesian analysis. The potential scale reduction factor (PSRF) and minimum and average effective sample sizes (ESS) for both the tree length and alpha parameters were 1.0 and $>5000$, respectively, for the post-burn-in trees, indicating that stationarity and convergence had been achieved.

\section{SYSTEMATIC PALEONTOLOGY}

Order: PERAMELEMORPHIA (Kirsch, 1968) Aplin
and Archer, 1987
Superfamily: Incertae sedis
Family: Incertae sedis

Genus: BULUNGU Gurovich et al., 2013

Type Species.- Bulungu palara Gurovich et al., 2013

\section{Revised Generic Diagnosis}

The species of Bulungu are small peramelemorphians (estimated body mass of $\sim 110-210$ grams) that differ from all others in the following combination of features: M3 preprotocrista terminates at the lingual base of paracone, resulting in an incomplete anterior cingulum on $\mathrm{M} 3$; posterior cingulum absent on M3; stylar cusp B (StB) on M3 large and oval with a crest present, but this crest does not connect to StD; StC present as a small cusp on M3 but StD1 is absent; metaconule small and never as lingually positioned as protocone (hence molars subtriangular rather than quadrilateral in occlusal outline); preentocristid anteroposteriorly-orientated on $\mathrm{m} 1-4$; no cuspids exist within hypoflexid region between talonid and trigonid on buccal side but a small shelf is present on m1-4; cristid obliqua contacts trigonid buccal to protoconid on $\mathrm{m} 1$, just lingual to protoconid on $\mathrm{m} 3$ and lingual to midpoint of metacristid on $\mathrm{m} 4$; paraconid- 
metaconid distance shorter than metaconid-protoconid distance in m2-3 but longer in $\mathrm{m} 4$; entoconid large on $\mathrm{m} 4$; posthypocristid oblique to tooth row axis on $\mathrm{m} 2$ but perpendicular on $\mathrm{m} 3$; talonid reduced on $\mathrm{m} 4$; molar crowns are distinct from roots.

The following combination of features seen in Bulungu palara may also be generically diagnostic, but is as yet unknown for other species in this genus (as they are currently known only from dental specimens): small canines; nasals extend posteriorly past anterior margin of orbit; two pairs of large palatal fenestrae present in palate posterior to incisive foramina; alisphenoid and parietal in contact on lateral wall of braincase (squamosalfrontal contact absent); sphenorbital fissure and foramen rotundum elongate and tube-like, not opening directly into endocranial cavity; primary foramen ovale very large and between petrosal and alisphenoid; bulbous alisphenoid tympanic wings cover anterolateral and medial sides of auditory recess; rostral tympanic process of petrosal an elongate ridge extending length of promontorium but without forming a hypotympanic sinus; epitympanic recess relatively shallow; an arch is formed by paroccipital and mastoid processes, through which is exposed part of the petrosal immediately posterior to fenestra cochleae; rim of postglenoid foramen formed almost exclusively by squamosal with only small contribution from petrosal; in posterior view, occiput is wider than high.

BULUNGU MUIRHEADAE, sp. nov.

Figures 1-2

http://zoobank.org/F7059F8F-F295-4AD2-908454874 CF57076

\section{Specific Diagnosis}

Bulungu muirheadae differs from Bulungu palara in the following combination of features: postparacrista and premetacrista contact each other, forming a complete centrocrista on M1-3; StC large on M1 (sometimes larger than StB); StD1 larger and distinct on $\mathrm{M} 1$ and $\mathrm{M} 2$; metaconule smaller and positioned more buccally on M1-3; preparacrista connects to StB on M2, but ends at the base of StA on M3; StE is a distinct cusp on M3; anterior cingulid present on $\mathrm{m} 1$; cristid obliqua terminates posterior to protoconid on $\mathrm{m} 2$; short postentocristid present on $\mathrm{m} 4$, and runs anteroposteriorly; posthypocristid is oblique to the tooth row axis on m4; hypoconulid present as small cusp on $\mathrm{m} 4$.

\section{Specific Etymology}

The species name honours vertebrate palaeontologist Jeanette Muirhead for her contribution to our understanding of fossil bandicoot taxonomy and evolution.

\section{Holotype}

QM F10666, left dentary with m1-3 (Figure 1).

\section{Paratypes}

QM F10668, left dentary fragment with $\mathrm{m} 4$ (Figure 1); QM F10669, right dentary fragment with m1-2 (Figure 1); UCR 15307, LM1 (Figure 2); QM F10664, LM2 (Figure 2); and UCR 15275, RM3 (Figure 2).

\section{Referred Material}

QM F10661, Rm1; QM F10662, RM3; QM F10665, RM3; QM F10667, right dentary with $\mathrm{m} 2-3$ and trigonid of m4; QM F12414, Rm3; QM F12415, Lm3; QM F12416, RM1; QM F12417, LM3; QM F12418, Lm3; QM F12419, Lm1; QM F12420, RM2; UCMP 108063, left maxilla fragment with M3; UCR 15266, Rm4; UCR 15268, Rm1; UCR 15270, LM3; UCR 15279, Lm2; UCR 15285, LM3; UCR 15299, RM2; UCR 15301, Lm2; UCR 15306, Rm3; UCR 15318, Lm2; UCR 15332, RM2; UCR 16996, LM1; UCR 17002, Lm3.

\section{Type Locality}

Tedford Locality (Site 2), site code RV 7230 , Lake Palankarinna, Etadunna Formation, Ditjimanka LF, Zone B.

\section{Age and Stratigraphy}

The Ditjimanka LF lies within Etadunna Faunal Zone B. Based on palaeomagnetic and drillcore data, Metzger and Retallack (2010) estimated the Etadunna Formation to span 26.1 to 23.6 m.y.a. The Ditjimanka LF is therefore late Oligocene in age.

\section{DESCRIPTION}

\section{Dentary}

Alveolar margin of the dentary increases in height from $p 1$ to $p 3$, decreases below $m 1$, and then increases again from $\mathrm{m} 2$ to $\mathrm{m} 4$ (Figure 1). Depth of ramus greatest below $\mathrm{m} 4$. Two short subequal diastemata present: first between the alveoli for $\mathrm{c} 1$ and $\mathrm{p} 3$; second between alveoli for $\mathrm{p} 1$ and p2. The symphysis extends as far as posterior alveolus for p2. Two mental foramina present. Anterior of these two is below diastema between 

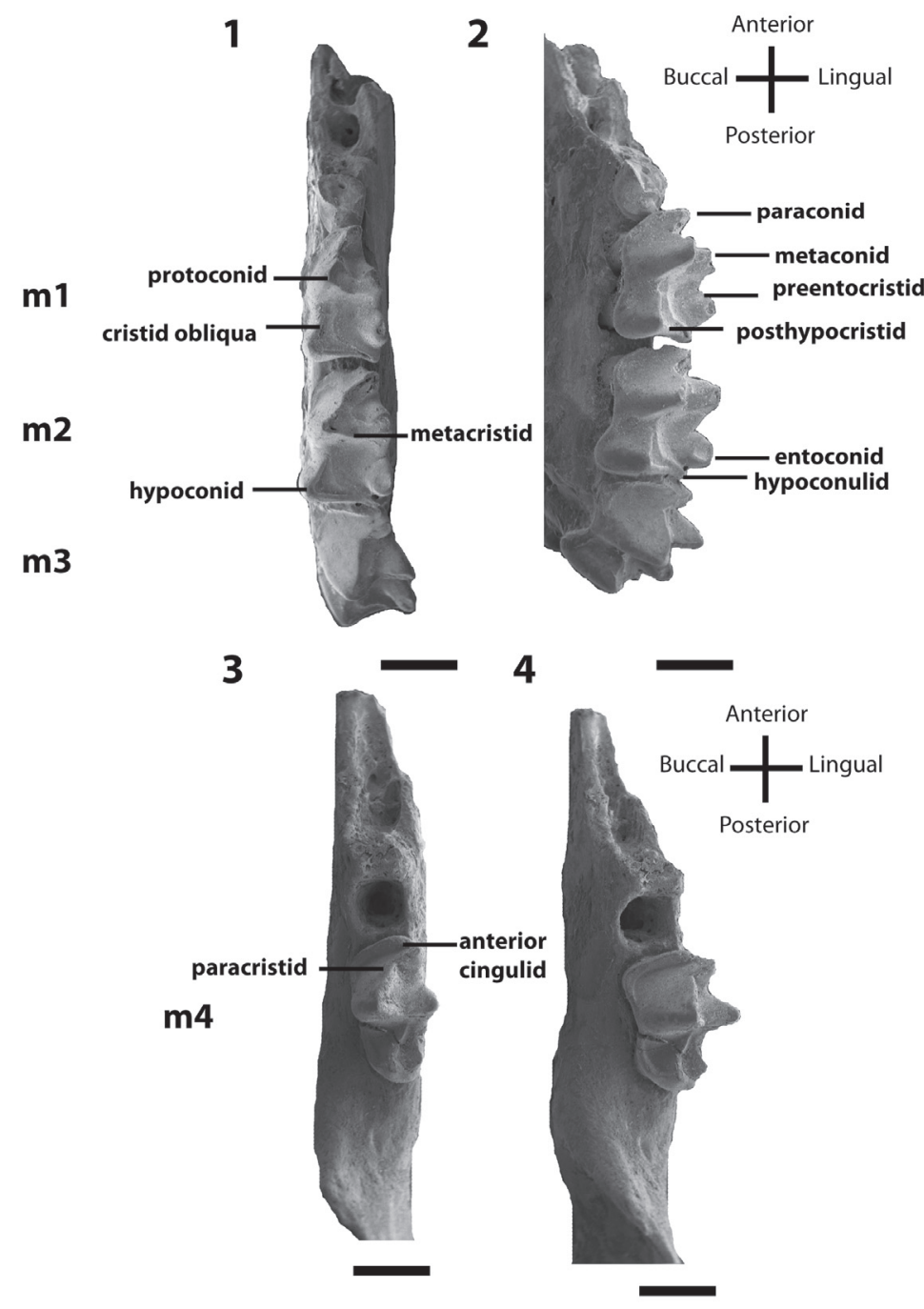

5

6
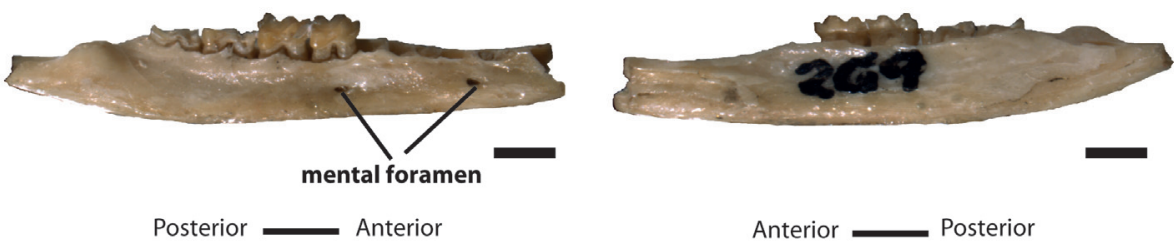

FIGURE 1. Bulungu muirheadae, sp. nov. Holotype QM F10666, 1, occlusal view of left dentary; 2, buccal view of left dentary. Paratype QM F10668, 3, occlusal view of left dentary; 4, buccal view of left dentary. Paratype QM F10669, 5, buccal view of right dentary; 6 , lingual view of right dentary. Scale bars for 1-4 equals $1 \mathrm{~mm}$, for 5-6 equals $2 \mathrm{~mm}$.

alveoli for $\mathrm{p} 1$ and $\mathrm{p} 2$; posterior foramen is below anterior alveolus for $\mathrm{m} 1$. Coronoid process forms an angle with body of dentary of approximately 120 degrees.

\section{Lower Dentition}

The description of $\mathrm{p} 3$ and $\mathrm{m} 1$ to $\mathrm{m} 3$ is based on QM F10666; that of $\mathrm{m} 4$ is based on QM F10668
(Figure 1). Only posterior part of $p 3$ is preserved. The posterior cusp is low and obscured by paraconid of $\mathrm{m} 1$. Posterior width of $\mathrm{p} 3$ narrower than trigonid of $\mathrm{m} 1$.

Protoconid and metaconid of $\mathrm{m} 1$ closer together than either is to paraconid. Protoconid tallest cusp on crown, followed by entoconid, metaconid, paraconid, hypoconid, and hypoconulid. A thin 


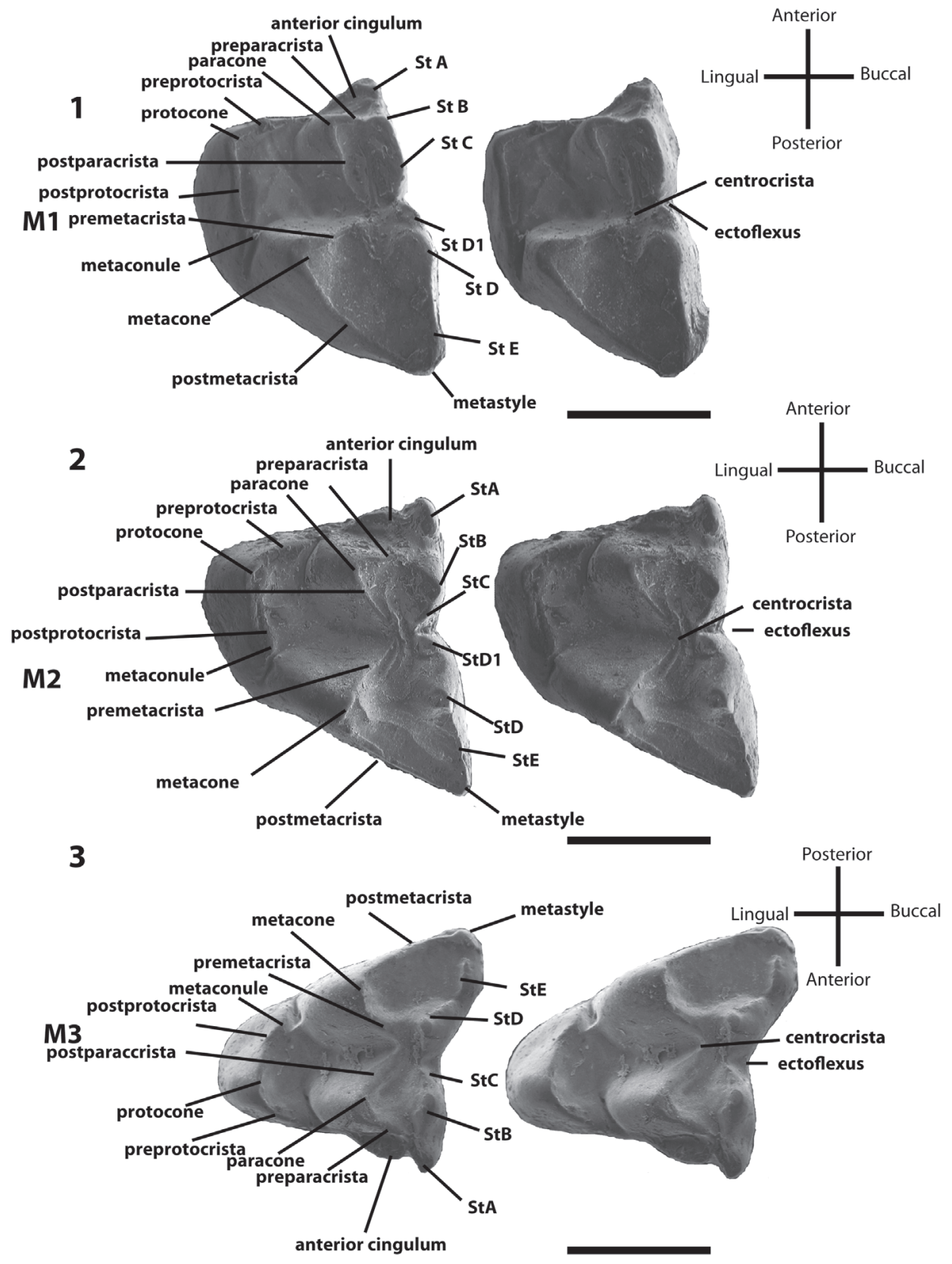

FIGURE 2. Bulungu muirheadae, sp. nov. Paratype UCR 15207, 1, occlusal view stereo pair of M1. Paratype QM F10664, 2, occlusal view stereo pair of M2. Paratype UCR 15275, 3, occlusal view stereo pair of M3. Scale bar equals $1 \mathrm{~mm}$.

anterior cingulid extends from buccal flank of paraconid to anterobuccal flank of protoconid. Paraconid anterobuccally positioned relative to metaconid. Metaconid posterolingually positioned with respect to protoconid. Talonid wider than trigonid. Entoconid is oval in shape, with short preentocristid connecting it to posterior flank of metaconid. Small cingulid-like hypoconulid, posterobuccal to entoconid, connects to hypoconid via posthypocristid. Almost linear cristid obliqua extends from hypoconid to posterobuccal flank of protoconid. Very small low ridge occurs posterobuccal to protoconid. Posterior cingulid absent.

Morphology of $\mathrm{m} 2$ similar to that of $\mathrm{m} 1$ except as follows. Paraconid more lingually positioned, almost directly anterior to metaconid. Protoconid more buccally-positioned increasing length of paracristid and metacristid. Distance between paraconid and metaconid relatively shorter. Anterior cingulid larger, extending further anterobuccally. 
Talonid wider with hypoconid positioned further anterobuccally, resulting in a longer posthypocristid, but shorter cristid obliqua. Angle formed by posthypocristid and cristid obliqua at hypoconid smaller. Cristid obliqua terminates more lingually, directly posterior to apex of protoconid. Entoconid is wider, almost conical, with short postentocristid running perpendicular to preentocristid. Postentocristid increases in length with wear.

Morphology of $\mathrm{m} 3$ similar to that of $\mathrm{m} 2$ except as follows. Paraconid-metaconid distance shorter. Talonid shorter, with hypoconid positioned further anteriorly, decreasing length of cristid obliqua. Entoconid shorter in length, almost completely conical, despite retaining preentocristid.

Morphology of $\mathrm{m} 4$ similar to that of $\mathrm{m} 3$ except as follows. Distance between paraconid and metaconid greater, almost equal to paraconid-protoconid distance and metaconid-protoconid distance. Talonid reduced, with hypoconid positioned posterolingual to protoconid. Hypoconulid small. Cristid obliqua longer than in $\mathrm{m} 3$ and terminates against trigonid posterior flank, level with midpoint between protoconid and metaconid. Angle between cristid obliqua and posthypocristid relatively wider. Entoconid small but taller than hypoconid. Well-defined preentocristid extends anteriorly from entoconid and ends against posterior flank of metaconid. A short postentocristid extends from tip of entoconid posteriorly to position just anterior to hypoconulid.

\section{Upper Dentition}

The description of M1 is based on UCR 15307 (Figure 2). It is anteroposteriorly longer than buccolingually wide. StD tallest cusp on crown. Small cusp (StD1, sensu Turnbull et al., 2003) immediately anterior to StD. Large StC very slightly smaller than StD and positioned anterior to StD1, immediately anterior to ectoflexus. A crest connects StD1 to StC through the ectoflexus and connects anteriorly to StB. Paracone directly lingual to StB; preparacrista connects these two cusps. Postparacrista longer than preparacrista and connects to premetacrista just lingual to ectoflexus. Premetacrista longer than postparacrista, but shorter than postmetacrista. Metacone directly lingual to StD. Distance between these two cusps twice as long as distance between StB and paracone. Postmetacrista ends at most posterobuccal end of tooth and connects to stylar crest, which connects StD to metastyle via small remnant of StE. Anteriorly to StD, this crest does not connect to StD1 but instead, curves lingually. StA/para- style just anterior to StB with small crest present running anteroposteriorly from most anterior part of tooth; this small crest ends prior to StB. Small anterior cingulum occurs lingual to StA, ending at a point just anterobuccal to paracone. Preprotocrista connects protocone to anterolingual base of paracone. Postprotocrista connects to small metaconule just lingual to base of metacone and ends posterolingual to latter. No posterior cingulum.

The description of M2 is based on QM F10664 (Figure 2). Morphology of M2 similar to that of M1except as follows. Crown wider, with protocone more lingually situated. Metaconule smaller and more buccally situated. StA taller. Larger, more anteriorly and more lingually situated anterior cingulum. Paracone more posterolingually situated, increasing length of preparacrista and reducing length of postparacrista. StB much taller, almost as tall as StD and more posteriorly situated, increasing distance between it and StA. Connection between preparacrista and StB weaker, with anterior part of StB more rounded. StC highly reduced and as tall as StD1. StE reduced, almost indistinguishable along stylar crest between StD and metastyle.

The description of M3 is based on UCR 15275 (Figure 2). Morphology of M3 similar to that of M2 except as follows. Crown wider than long, with protocone more lingually situated. Anterior cingulum larger and more anteriorly extensive. Crest running through StA anteroposteriorly connects to anterior flank of StB. Preparacrista runs toward midpoint of StA's crest before curving anteriorly parallel to this crest, ending below StA. Angle between preparacrista and postparacrista wider. StC minute, barely visible above crest connecting StB to StD. StD1 absent. StE distinct, taller cusp. StE and metastyle more buccally situated, elongating postmetacrista. No stylar crest runs between StD and StE.

Measurements of upper and lower dentitions presented in Tables 1-2. Average body mass estimated to 135.58 grams.

\section{BULUNGU CAMPBELLI, sp. nov.} Figure 3

\section{http://zoobank.org/15133E7C-0456-46F3-8DE0-} A2CF72C6A006

\section{Specific Diagnosis}

Bulungu campbelli differs from $B$. palara and $B$. muirheadae in the following combination of features: StA and StB connected by a crest on M3; StE absent on M3; postparacrista and premetacrista not connected to form a complete centrocrista 


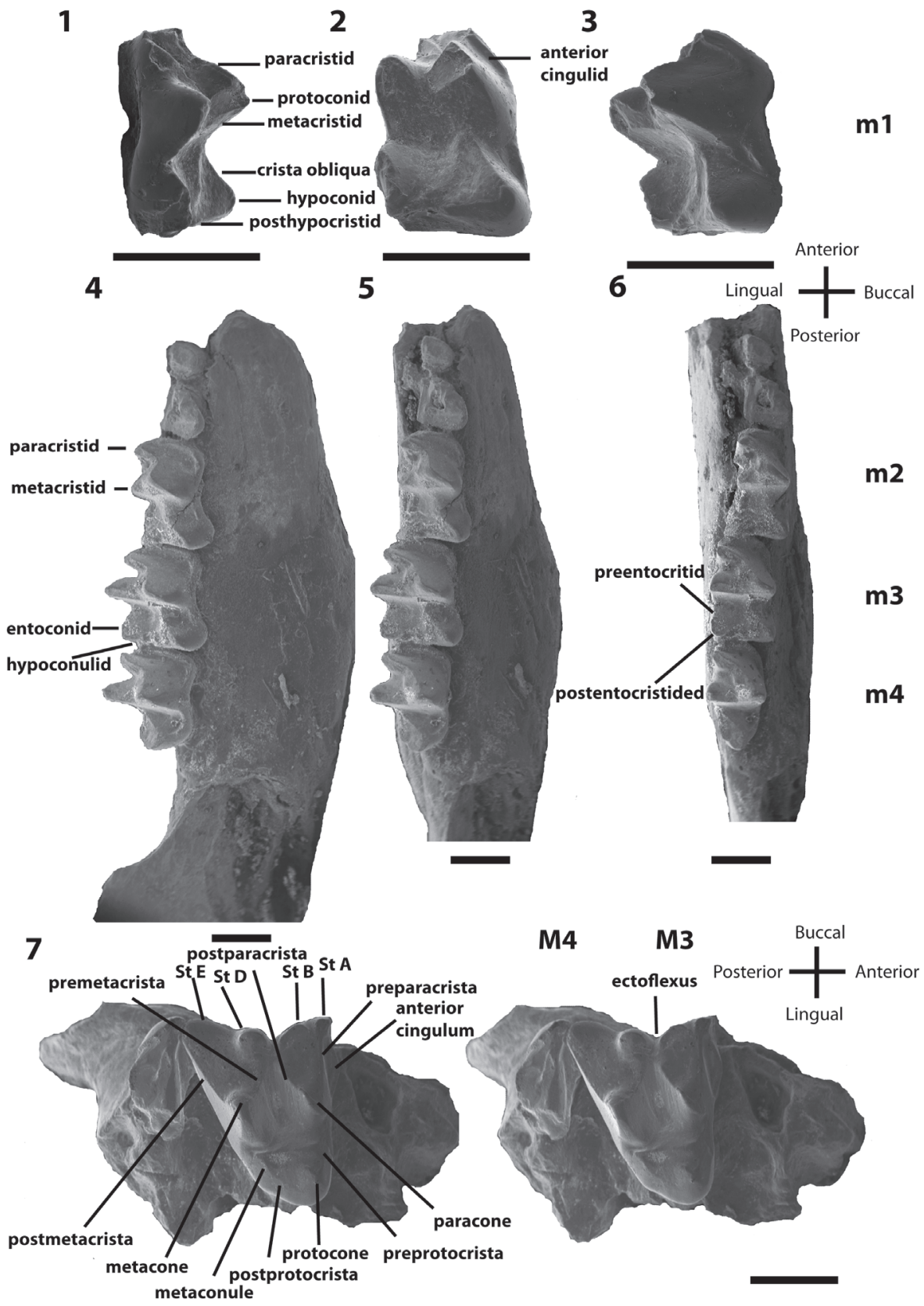

FIGURE 3. Bulungu campbelli, sp. nov. Holotype SAM P13853, 1, lingual view of $\mathrm{m} 1$; 2, occlusal view of $\mathrm{m} 1$; 3, buccal view of $\mathrm{m} 1 ; \mathbf{4}$, buccal view of right dentary; $\mathbf{5}$, buccal/occlusal view of right dentary; $\mathbf{6}$, occlusal view of right dentary; 7 , stereo pair of occlusal view of right maxilla. Scale bar equals $1 \mathrm{~mm}$.

on $M 3$, but instead postparacrista ends on lingual flank of StC, and premetacrista ends on lingual flank of StD; metaconule on M3 minute and situated on lingual flank of metacone; metacristid perpendicular to tooth row on $\mathrm{m} 3$ only; postentocristid present; talonid slightly longer anteroposteriorly than trigonid on $\mathrm{m} 3$.

\section{Specific Etymology}

The species name honours vertebrate palaeontologist Colin Campbell for his significant contributions to peramelemorphian systematics and in particular the preliminary analysis in his $\mathrm{PhD}$ thesis (Campbell, 1976) of specimens referable to the taxa named and described here. 


\section{Holotype}

SAM P13853, right dentary with m1-4 (Figure 3 ) and associated right maxilla fragment with $M 3$ and partial M4 (Figure 3).

\section{Type Locality}

Ngapakaldi Quarry, site code V 5858, Lake Ngapakaldi, Etadunna Formation, Ngapakaldi LF, Zone C.

\section{Age and Stratigraphy}

The Ngapakaldi LF, (Etadunna Zone C) was regarded by Woodburne et al. (1993) to be late Oligocene in age, between 24-26 m.y.a. Based on palaeomagnetic and drill-core data, Metzger and Retallack (2010) estimated the Etadunna Formation to span from 26.1 to 23.6 m.y.a. The Ngapakaldi LF is therefore late Oligocene in age, but younger than the underlying Ditjimanka LF (Etadunna Zone B).

\section{DESCRIPTION}

\section{Dentary}

Dentary poorly preserved, missing anterior section from the anterior root of $\mathrm{m} 1$ (Figure 3). Posterior part of dentary also missing. Preserved base of coronoid process forms an angle of 120 degrees with the ramus. Dentary is deepest below m3.

\section{Lower Dentition}

Only molars preserved. The $\mathrm{m} 1$ (originally intact in the dentary but now loose) roots are preserved in the alveoli. Anterior root smaller and rounder than posterior root (Figure 3). All cusps except hypoconid damaged at tips. Protoconid tallest cusp followed (in decreasing order) by metaconid, entoconid, paraconid, hypoconid, and hypoconulid (Figure 3). Narrow anterior cingulid damaged on anterolingual side of tooth. Very little of paraconid preserved. In occlusal view, paraconid anterolingual to protoconid and anterobuccal to metaconid. Metaconid posterolingual to protoconid; hence, metacristid not perpendicular to tooth row. Hypoconid positioned posterobuccal to protoconid. Cristid obliqua departs obliquely from tip of hypoconid and terminates on posterior flank of protoconid. Hypoflexid present as a small shelf between buccal flank of protoconid and anterior flank of hypoconid. Steeply inclined posthypocristid connects hypoconid to hypoconulid. Very little of hypoconulid preserved but would have been directly posterior to entoconid. Entoconid directly posterior to metaconid. Entoconid narrow, with preentocristid visible on undamaged anterior surface; preentocristid terminates within valley separating entoconid and metaconid. Talonid wider than trigonid. No posterior cingulid.

The morphology of $\mathrm{m} 2$ resembles that of $\mathrm{m} 1$ except as follows. Anterior cingulid of $\mathrm{m} 2$ extends from base of paraconid, perpendicular to tooth row, then curves posterobuccally toward base of protoconid (Figure 3). Trigonid narrow, with metaconid and paraconid closer to each other than either is to protoconid. Distance between paraconid and protoconid greater than distance between metaconid and protoconid. Entoconid highly worn or damaged. Cristid obliqua terminates below centre of metacristid.

The morphology of $\mathrm{m} 3$ resembles that of $\mathrm{m} 2$ except as follows (Figure 3). Paraconid and metaconid closer together, narrowing trigonid. Metacristid perpendicular to tooth row and parallel to posthypocristid. Metaconid tallest cusp, followed by entoconid, protoconid, paraconid, hypoconulid and hypoconid. Preentocristid connects entoconid to posterior base of metaconid. Entoconid wider posteriorly than anteriorly, almost teardrop-shaped. Short crest (postentocristid) runs at an angle buccally, almost perpendicular to tooth row, and ends near base of entoconid. Trigonid and talonid wider but shorter in length than on $\mathrm{m} 2$.

The morphology of $\mathrm{m} 4$ resembles that of $\mathrm{m} 3$ except as follows (Figure 3). Distances between paraconid and protoconid, and metaconid and protoconid all shorter. Angle formed by trigonid blades wider. Metaconid remains tallest cusp but followed by protoconid, paraconid, entoconid, hypoconid, and hypoconulid. Talonid reduced. Hypoconid more lingually situated, almost level with middle of metacristid. Very small hypoconulid posterobuccal to entoconid. These two cusps connected by postentocristid. Cristid obliqua runs anteriorly from the posterior flank of the trigonid, just buccal to the anterior tip of preentocristid and ends posteriorly at the tip of hypoconid, joining with posthypocristid at 120 degree angle. Posthypocristid ends at posterior extremity of tooth.

\section{Upper Dentition}

The maxilla (Figure 3 ) is poorly preserved. Only the alveoli for M2, the M3, and the anterior tip of M4 are preserved.

M3 is wider than long (Figure 3). Preparacrista extends from paracone in a buccal direction then curves anteriorly to join StA. A stylar crest extends from tip of StA posteriorly, then curves lingually 


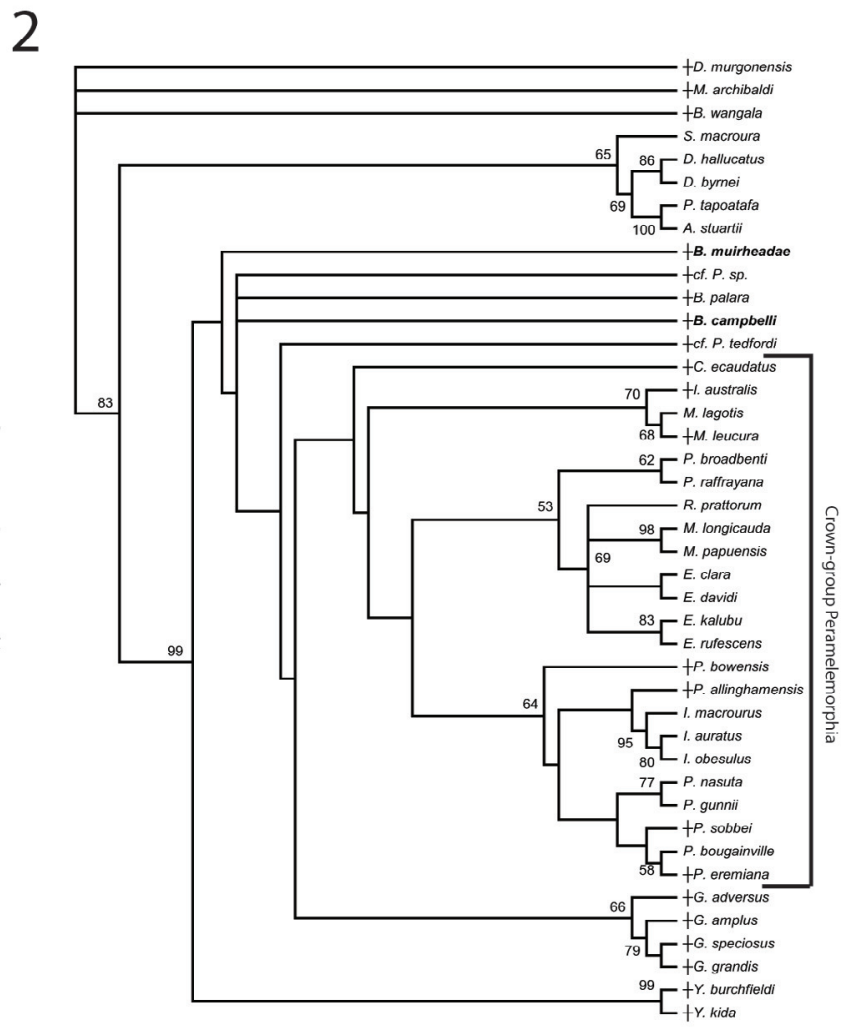

FIGURE 4. Phylogenetic relationships of Bulungu muirheadae and B. campbelli sp. nov. based on our 156 character craniodental matrix. Fossil and recently extinct taxa are indicated by $\dagger$. Bulungu muirheadae and $B$. campbelli are highlighted in bold. Crown-group Peramelemorphia is bracketed. 1, strict consensus of 8 most parsimonious trees (tree length $=889$; consistency index excluding uninformative characters $=0.3412$; retention index $=0.6560$ ) from unconstrained maximum parsimony analysis of the matrix. Numbers above branches represent bootstrap values (1000 replicates); numbers below branches represent decay indices. 2, strict consensus of 24 most parsimonious trees (tree length $=917$; consistency index excluding uninformative characters $=0.3308$; retention index 0.6395 ) that result when the matrix is analysed using maximum parsimony and enforcing a "backbone" molecular scaffold based on Westerman et al. (2012).

before curving again at the posterior flank of StA buccally to connect to tip of StB. This crest then continues posteriorly through a minute $\mathrm{StC}$ and ends prior to reaching the ectoflexus region. StD1 absent. No stylar crest connects StD to metastyle. StE absent. Postparacrista straight, obliquely orientated and ends at base of posterolingual flank of StC. Postparacrista does not join premetacrista, and hence the centrocrista is incomplete. Premetacrista ends at anterolingual base of flank of StD. Postmetacrista longest crest and runs from metacone to metastyle. Anterior cingulum is wide and runs lingually from lingual flank below StA to almost level with middle of preparacrista. Protocone posterolingual to paracone. Preprotocrista runs parallel to preparacrista from anterior flank of paracone to protocone, and forms an angle of almost 90 degrees with postprotocrista. Postprotocrista then curves posteriorly almost parallel to tooth row and joins small metaconule, before ending on lingual flank of metacone. Metaconule directly lingual to metacone. Posterior cingulum absent.

Very little of M4 is preserved (Figure 3). What can be seen resembles the anterior part of M3 but differs as follows. StA large and tall. Preparacrista runs from paracone to StA, parallel to preparacrista of M3. Stylar crest runs obliquely from StA to the broken edge of the tooth. Morphology of anterior cingulum same as in M3.

Measurements of the upper dentition of $B$. campbelli are presented in Table 1 and of the lower dentition in Table 2. Average body mass estimated to 112.87 grams.

\section{RESULTS}

Unconstrained maximum parsimony analysis of our 156 craniodental character matrix recovered 

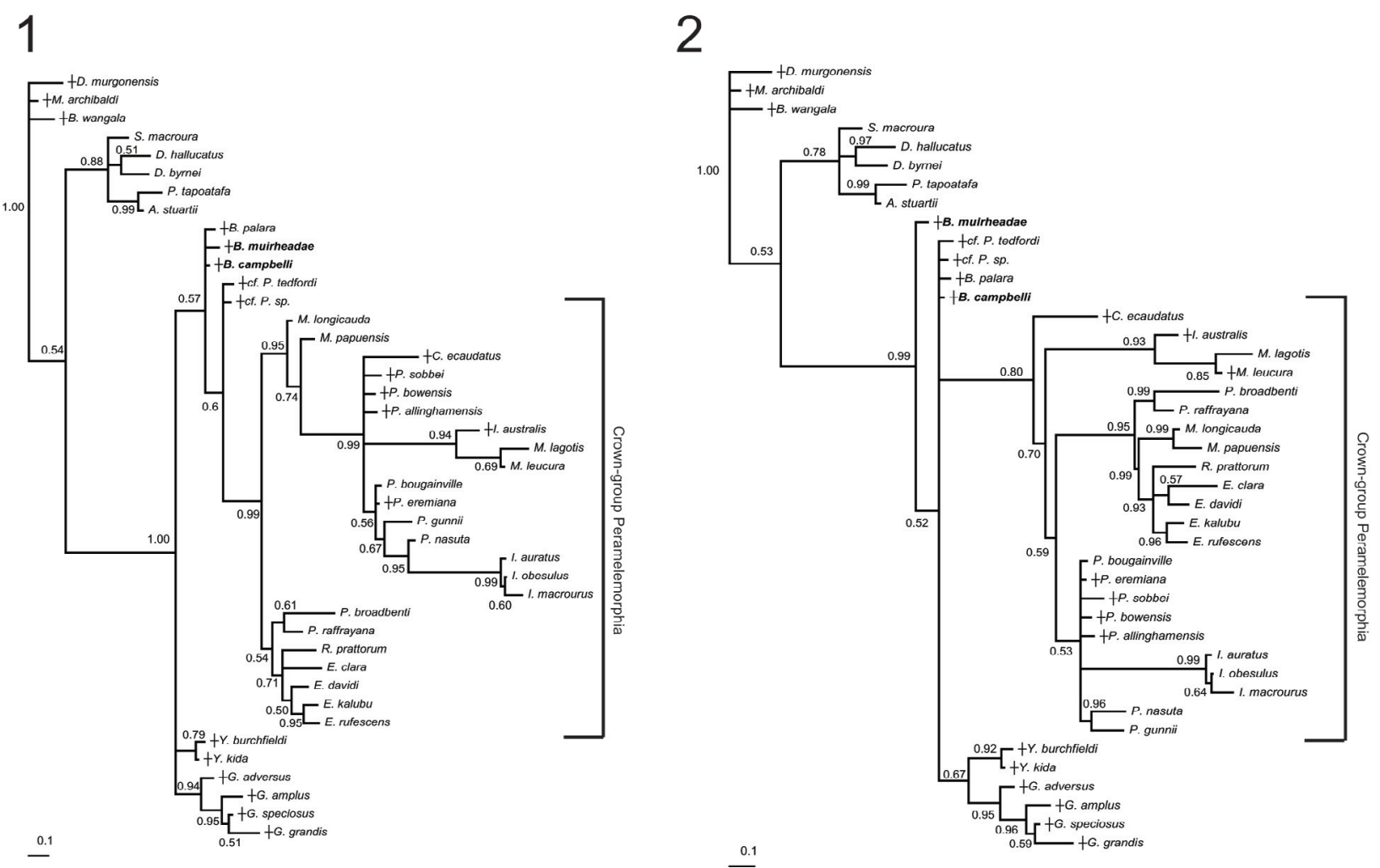

FIGURE 5. Phylogenetic relationships of Bulungu muirheadae and B. campbelli sp. nov. based on our 156 character craniodental matrix. Fossil and recently extinct taxa are indicated by $\uparrow$. Bulungu muirheadae and $B$. campbelli are highlighted in bold. Crown-group Peramelemorphia is bracketed. 1, 50\% majority rule consensus that results after Bayesian analysis of the matrix assuming the $\mathrm{Mk}+\mathrm{G}$ model (harmonic mean of the log likelihood of the post-burn-in trees $=-2898.10$ ). The analysis was run for five million generations, sampling trees every 100 generations, with a "burn-in" period of 1.25 million generations. Numbers above branches represent Bayesian posterior probabilities. 2, $50 \%$ majority rule consensus that results after Bayesian analysis of the matrix is analysed enforcing a "backbone" molecular scaffold based on Westerman et al. (2012), assuming the Mk + G model (harmonic mean of the log likelihood of the post-burn-in trees $=-2933.45$ ). The analysis was run for five million generations, sampling trees every 100 generations, with a "burn-in" period of 1.25 million generations. Numbers above branches represent Bayesian posterior probabilities.

8 most parsimonious trees of 889 steps; the strict consensus of these is illustrated in Figure 4.1, with bootstrap values above the branches and decay indices below. Parsimony analysis of the same matrix but enforcing a molecular scaffold as a "backbone" constraint recovered 24 most parsimonious trees of 917 steps, the strict consensus of which is given in Figure 4.2, with bootstrap values given above the branches. Unconstrained Bayesian analysis of the same matrix resulted in a postburn-in log likelihood (harmonic mean) of -2898.10, whereas the post-burn-in log likelihood for the Bayesian analysis with the molecular scaffold enforced was -2933.45 ; the $50 \%$ majority rule consensuses from the unconstrained and molecular scaffold Bayesian analyses are given in Figures
5.1 and 5.2, respectively, with Bayesian posterior probabilities given at the nodes.

In all four phylogenetic analyses presented here, Bulungu campbelli and $B$. muirheadae lie outside crown-group Peramelemorphia. Monophyly of Bulungu is recovered in the unconstrained maximum parsimony analysis, but with weak support (bootstrap $<50 \%$; decay index +1 ; Figure 4.1 ). However, the relationships of the three Bulungu species are unresolved in the unconstrained Bayesian analysis (Figure 5.1), and B. palara and $B$. campbelli are recovered as closer to the crowngroup than is $B$. muirheadae in both parsimony and Bayesian analyses when a molecular scaffold is enforced (Figures 4.2, 5.2). The other Oligo-Miocene bandicoot taxa described to date, namely Yarala burchfieldi, Y. kida and the four species of 
Galadi also lie outside crown-group Peramelemorphia in all four analyses, in agreement with the results of previous phylogenetic analyses (Travouillon et al., 2010; 2013; Gurovich et al., 2013). Monophyly of Yarala and Galadi is also relatively strongly supported in all four analyses. However, the relative branching order of Bulungu, Yarala and Galadi varies between the analyses, with Bulungu closer to the crown-group in the unconstrained parsimony and Bayesian analyses but more distant when a molecular scaffold was enforced.

Another notable feature of our analyses is the fact that the two bandicoot taxa described by Turnbull et al. (2003) from the early Pliocene Hamilton Fauna, namely cf. Peroryctes tedfordi and cf. Peroryctes sp., consistently fall outside the crowngroup. In the unconstrained maximum parsimony analysis, these taxa form a clade with Bulungu, although this is not the case in the other three analyses. Based on these results, we believe that referral of these Pliocene taxa to Peroryctes is unjustified and that they are more likely late-surviving stem-peramelemorphians; if so, all known records of Peroryctes are from New Guinea, and crown-group peramelemorphians do not appear to be present in the Hamilton LF.

However, in contrast to the results of a previous study (Gurovich et al., 2013), analyses of our revised and expanded craniodental matrix consistently place the Pliocene Ischnodon australis in a clade with the Recent thylacomyids Macrotis lagotis and $M$. leucura with moderate-to-strong support, supporting the referral of Ischnodon to Thylacomyidae. The other Pliocene peramelemorphians, namely Perameles allinghamensis and $P$. bowensis, and the Pleistocene $P$. sobbei also consistently fall within the crown-group, and in all but the unconstrained Bayesian analysis form a clade with Recent Perameles and Isoodon species (albeit with weak support); thus, our results confirm that $P$. allinghamensis and $P$. bowensis represent the oldest known records of the family Peramelidae (Peramelinae sensu Wilson and Reeder, 2005).

Our unconstrained maximum parsimony analysis shows greater congruence with current molecular phylogenies than do previous morphological analyses: monophyly of Peramelidae (i.e., Perameles + Isoodon; = Peramelinae sensu Wilson and Reeder, 2005) to the exclusion of Chaeropus and thylacomyids, and of Peroryctidae (i.e., Echymipera+Microperoryctes + Rhynchomeles + Peroryc-

tes) is supported, although Chaeropus and Thylacomyidae are placed as successive sister- taxa to Peramelidae, rather than outside Peramelidae and Peroryctidae, as is the case in recent molecular phylogenies. By contrast, the unconstrained Bayesian analysis shows greater conflict: Peramelidae is not recovered as monophyletic to the exclusion of Chaeropus and thylacomyids, and Peroryctidae is recovered as paraphyletic. Nevertheless, the parsimony results are encouraging, and suggest that the increased taxon and character sampling in our craniodental matrix presented here has reduced the incongruence between morphological and molecular estimates of peramelemorphian phylogeny.

\section{DISCUSSION}

The origin of Peramelemorphia, like all marsupial orders in Australia, remains unclear. Recent phylogenetic analyses of higher-level marsupial relationships consistently place Peramelemorphia in a clade together with Dasyuromorphia and Notoryctemorphia (Beck, 2008, 2012; Beck et al., 2008b; Meredith et al., 2008, 2009, 2011; Nilsson et al., 2004), but the precise branching order between these three orders remains unclear. The oldest potential fossil record of Peramelemorphia may be as yet undescribed early Eocene specimens from the Tingamarra LF, near Murgon, southeastern Queensland (Black et al., 2012). Prior to the current paper, the oldest described bandicoot species were Yarala kida from the late Oligocene or early Miocene Kangaroo Well LF in the Northern Territory (Schwartz, 2006) and Y. burchfieldi, Bulungu palara, Galadi speciosus, G. adversus, $G$. Amplus, and $G$. adversus from early to late Miocene LFs of the Riversleigh WHA.

Fossil bandicoots from the late Oligocene Etadunna and early Miocene Wipajiri Formations of the Lake Eyre Basin, have been reported (Campbell, 1976; Woodburne et al., 1993; Case, 2001) but until now none has been formally described. Campbell (1976) reported two taxa: one small taxon from Zones B (Ditjimanka LF) and C (Ngapakaldi LF) and the Kutjamarpu LF (early Miocene), and one large taxon from the Kutjamarpu LF. The taxa described in this current paper and in Gurovich et al. (2013) are based on samples that include the specimens Campbell (1976) referred to the small species. With the advantage of additional specimens collected since Campbell's study, we have concluded that this material represents three distinct taxa: Bulungu muirheadae from the Ditjimanka LF (this work), B. campbelli from the Ngapakaldi LF (this work), and B. palara from the Kutjamarpu and several Riversleigh LFs 
(Gurovich et al., 2013). Campbell's (1976) large species remains undescribed. It appears to be unique to the Kutjamarpu LF. However, we have identified a third species from the Kutjamarpu LF that is also known from Riversleigh Faunal Zone B (early Miocene) and C (mid Miocene) LFs. Woodburne et al. (1993) and Case (2001) note but do not name other peramelemorphian specimens from the Etadunna and Wipajiri Formations. Pending formal description of these specimens, their relationships to taxa described in this work remain uncertain.

The dental morphology (tribosphenic dentition, lacking development of the metaconule) and size of Bulungu campbelli ( 112.87 grams, this work) and $B$. muirheadae ( 135.58 grams, this work) is similar to that of $B$. palara $(\sim 130$ grams, Gurovich et al., 2013) suggesting that they were small insectivores. Gurovich et al., 2013 noted that $B$. palara, along with Yarala burchfieldi ( 75 grams, Travouillon et al., 2009) and Y. kida (Schwartz et al., 2006) were smaller than any living species of bandicoot. B. muirheadae and B. campbelli add to the diversity of small bodied bandicoots, which provide further support that OligoMiocene Australian peramelemorphians filled ecological niches that today are mostly occupied by dasyurids (Muirhead, 1994, 2000; Muirhead and Filan, 1995; Schwartz, 2006; Travouillon et al., 2010, 2013; Gurovich et al., 2013).

Bulungu muirheadae appears to be more plesiomorphic than either $B$. campbelli or $B$. palara in its retention of complete centrocristae on all upper molars. This is supported by two of our four phylogenetic analyses, where Bulungu muirheadae branches of earlier than the other two Bulungu species (Figures 4-5). Based on their craniodental morphology all of the Oligo-Miocene fossil peramelemorphians described to date, including Bulungu campbelli and $B$. muirheadae from the Etadunna formation described here, appear more plesiomorphic than any extant bandicoot (Muirhead and Filan, 1995; Muirhead, 2000; Travouillon et al., 2010, 2013; Gurovich et al., 2013). Previous studies (Travouillon et al., 2010, 2013; Gurovich et al., 2013), as well as the results of the more comprehensive phylogenetic analyses presented here (Figures 4-5), also suggest that all of these taxa lie outside crown-group Peramelemorphia. Our results indicate that the oldest described crown-group bandicoots are early Pliocene in age, namely the thylacomyid Ischnodon australis and the peramelids Perameles allinghamensis and $P$. bowensis.
These results appear to be in conflict with dated molecular phylogenies, which suggest that the earliest divergences among crown-group peramelemorphians occurred $>20$ m.y.a. (Meredith et al., 2008) or even 27 m.y.a. or older, depending on the method and calibrations used (Meredith et al., 2008, 2011; Westerman et al., 2012). These relatively ancient estimated divergence dates are possible, given the relatively scanty nature of the peramelemorphian fossil record and despite recent improvements in our knowledge. Nevertheless, if the South Australian, Northern Territory and Queensland Oligocene and Miocene fossil assemblages described to date are truly representative of peramelemorphian diversity at that time, this would imply that crown-group peramelemorphians were either much rarer than their stem-relatives or were restricted to geographical areas that have yet to be sampled, such as Western Australia. However, it should be noted that additional fossil species from Riversleigh (Archer et al., 2006) and the Lake Eyre Basin (Case, 2001) remain to be described, and could potentially include crown-group taxa.

Alternatively, it is possible that the molecular divergence dates are overestimates (see Gurovich et al., 2013). The latter possibility is perhaps rendered more likely by the fact that both Meredith et al. (2008) and Westerman et al. (2012) used "cf. Peroryctes" tedfordi and "cf. Peroryctes" sp. from the early Pliocene Hamilton fauna (Turnbull et al., 2003) to calibrate the split between Peroryctes (= Peroryctinae) and Echymipera+Microperoryctes (= Echymiperinae), whereas our phylogenetic analyses consistently place "cf. Peroryctes" tedfordi and "cf. Peroryctes" sp. outside crown-group Peramelemorphia, and hence neither fossil taxon is suitable for calibrating divergences within the crown-group (see below). As we note above, according to the results of our phylogenetic analyses, the oldest known crown-group peramelemorphians are the early Pliocene Ischnodon australis and the early Pliocene peramelids Perameles allinghamensis and $P$. bowensis, which, we argue, are suitable for specifying minimum dates for the Thylacomyidae-(Peramelidae+Peroryctidae) and Peramelidae-Peroryctidae splits, respectively. Although beyond the scope of the current paper, it would be interesting to see what impact the use of these alternative calibrations has on molecular divergence dates.

Given the occurrence of crown-group peramelemorphian clades in the Pliocene, namely Thylacomyidae (represented by Ischnodon australis) and Peramelidae (represented by Perameles all- 
inghamensis and $P$. bowensis), it seems that these more modern groups had begun to supplant the archaic stem-lineages by this time, probably following a rapid but poorly documented interval of diversification in the late Miocene. Nevertheless, some stem-peramelemorphians appear to have survived this apparent late Miocene faunal turnover event, as indicated by the presence of "cf. Peroryctes" tedfordi and "cf. Peroryctes" sp. (both of which were consistently recovered outside the crowngroup in our phylogenetic analyses) in the early Pliocene Hamilton LF. Interestingly, Hocknull (2005) described two peramelemorphian species from middle Pleistocene (Hocknull et al., 2007) cave deposits at Mount Etna, central-eastern Queensland that could not be referred to any modern family. Hocknull (2005) noted similarities between these species and both "cf. Peroryctes" tedfordi and Yarala burchfieldi. It is therefore possible that stem-peramelemorphians survived in Australia until at least the middle Pleistocene, perhaps going extinct with the onset of more xeric conditions some time after 280,000 years ago (Hocknull et al., 2007). It is worth mentioning that both Hamilton LF and the middle Pleistocene cave deposits at Mount Etna have been interpreted as rainforest environments. This could potentially suggest that stem-peramelemorphians were adapted to rainforest environments and that they survived in these relictual habitats.

If the early Pliocene "cf. Peroryctes" tedfordi and "cf. Peroryctes" sp. and the two middle Pleistocene peramelemorphian species described by Hocknull (2005: 78) belong to stem-Peramelemorphia rather than to the extant family Peroryctidae, then peroryctids are currently unknown from Australia, with the sole exception of the extant Echymipera rufescens, which appears to have dispersed to Australia from New Guinea during the Plio-Pleistocene. Thus, it is possible that the early evolutionary of peroryctids was restricted to New Guinea (contra Westerman et al., 2012). However, this hypothesis must be weighed against geological evidence (Quarles van Ufford and Cloos, 2005, summarised by Westerman et al., 2012) that suggests that only small areas of land were emergent off the north coast of the Australian continent prior to $\sim 12$ m.y.a., and that these were separated from Australia by deepwater barriers. In this context, accurate estimates of divergence times within Peramelemorphia and other marsupial clades (e.g., Pseudocheiridae, Meredith et al., 2009; Phalangeridae, Raterman et al., 2006) will be key to under- standing the differential roles that the Australian mainland and New Guinea played in the diversification of marsupials in the Australo-Papuan region. Given the essential role that fossils play in calibrating molecular divergence dates, a better understanding of the fossil record and phylogeny of Peramelemorphia will be crucial to this endeavour, as will improvements in molecular sampling and methods (dos Reis et al., 2012).

In terms of overall peramelemorphian diversity through time, although inferences based on raw taxon counts (which do not take into account geological, taphonomic, collecting or other biases) should be treated as highly tentative, taxonomic diversity appears to have been relatively low during the late Oligocene, with no more than two species known from any one site (Case, 2001). In the early Miocene, diversity seems to have significantly increased, with some Riversleigh fossil localities containing seven different species (Archer et al., 2006). In the middle Miocene, a maximum of five species have been recorded at Gag Site at Riversleigh. In the late Miocene, two species have been reported from Encore Site in Riversleigh (Myers et al., 2001) and two specimens (unclear whether these specimens represent 1 or 2 species) from Alcoota (Murray and Megirian, 1992). Whether the apparent drop in peramelemorphian diversity seen in the late Miocene is related to the inferred faunal turnover event discussed above will require more detailed study of appropriately aged sites; unfortunately, the late Miocene vertebrate fossil record is poorly known in Australia, particularly for small mammals (Archer et al., 1999).

\section{CONCLUSIONS}

Two small, insectivorous peramelemorphian marsupials, Bulungu muirheadae and B. campbelli, are described from the late Oligocene of the Etadunna Formation, one from the Ditjimanka LF and one from the Ngapakaldi LF in central Australia. These two are related to a third species, Bulungu palara, from the Miocene Kutjamarpu LF of central Australia and several LFs from Riversleigh in northwestern Queensland. The two new species are currently among the oldest formally described bandicoots. The results of our phylogenetic analysis also reveal that early Pliocene "cf. Peroryctes" tedfordi and "cf. Peroryctes" sp. from Hamilton LF belong to stem-Peramelemorphia rather than to the extant family Peroryctidae. 


\section{ACKNOWLEDGMENTS}

Support for research at Riversleigh has come from the Australian Research Council (DP0453262, LP0453664, LP0989969 and LP100200486 grants to M. Archer and S.J. Hand and DE120100957 to R.M.D. Beck at the University of New South Wales); XSTRATA Community Partnership Program (North Queensland); the University of New South Wales; Phil Creaser and the CREATE Fund, the Queensland National Parks and Wildlife Service; Environment Australia; the Queensland Museum; the Riversleigh Society Inc.; Outback at Isa; Mount Isa City Council; and private supporters including K. and M. Pettit, E. Clark, M. Beavis and M. Dickson. Assistance in the field has come from many hundreds of volunteers as well as staff and postgraduate students of the University of New South Wales. Assistance in central Australia came from the University of California, Berkeley with significant input in the field from $\mathrm{C}$. Campbell, M. Woodburne and B. Clemens. We thank C. Campbell for enabling us to study the bandicoots he examined during his $\mathrm{PhD}$ research. We thank R. Day for providing funding to the University of Queensland to create a postdoctoral position for K.J. Travouillon. We thank S. Ingleby and A. Divljan from the Australian Museum, $\mathrm{H}$. Janetzki from the Queensland Museum and C. Stevenson from the Western Australian Museum for providing access to the modern bandicoot collections. We thank the UNSW Palaeosciences Lab and the UQ Palaeo Hub for their support and anonymous reviewers for helpful comments.

\section{REFERENCES}

Aplin, K.P. and Archer, M. 1987. Recent advances in marsupial systematics with a new syncretic classification, p. xv-Ixxii. In Archer, M. (ed.), Possums and Opossums, Studies in Evolution. Surrey Beatty and Sons, Sydney, Australia.

Archer, M. 1976. The dasyurid dentition and its relationships to that of didelphids, thylacinids and borhyaenids. Australian Journal of Zoology, Supplementary Series 39:1-34.

Archer, M. and Wade, M. 1976. Results of the Ray E. Lemley expeditions, part 1: The Allingham Formation and a new Pliocene vertebrate fauna from northern Queensland. Memoirs of the Queensland Museum, 17:54-58.

Archer, M., Arena, D.A., Bassarova, M., Beck, R.M.D., Black, K., Boles, W.E., Brewer, P., Cooke, B.N., Crosby, K., Gillespie, A., Godthelp, H., Hand, S.J., Kear, B.P., Louys, J., Morrell, A., Muirhead, J., Roberts, K.K., Scanlon, J.D., Travouillon, K.J., and
Wroe, S. 2006. Current status of species-level representation in faunas from selected fossil localities in the Riversleigh World Heritage Area, northwestern Queensland. Alcheringa Special Issue, 1: 1-17.

Archer, M., Arena, R., Bassarova, M., Black, K., Brammall, J., Cooke, B., Creaser, P., Crosby, K., Gillespie, A., Godthelp, G., Gott, M., Hand, S.J., Kear, B., Krikmann, A., Mackness, B., Muirhead, J., Musser, A., Myers, T., Pledge, N., Wang, Y., and Wroe, S. 1999. The evolutionary history and diversity of Australian mammals. Australian Mammalogy, 21:1-45.

Beck, R.M.D. 2008. A dated phylogeny of marsupials using a molecular supermatrix and multiple fossil constraints. Journal of Mammalogy, 89:175-189.

Beck, R.M.D. 2012. An 'ameridelphian' marsupial from the early Eocene of Australia supports a complex model of Southern Hemisphere marsupial biogeography. Naturwissenschaften, 99:715-29.

Beck, R.M.D., Godthelp, H., Weisbecker, V., Archer, M., and Hand, S.J. 2008b. Australia's oldest marsupial fossil and their biogeographical implications. PloS ONE, 3:e1858.

Beck, R.M.D., Archer, M., Godthelp, H., Mackness, B.S., Hand, S.J., and Muirhead, J. 2008a. A bizarre new family of Marsupialia (Incertae sedis) from the early Pliocene of northeastern Australia: implications for the phylogeny of bunodont marsupials. Journal of Paleontology, 82:749-762.

Black, K.H., Archer, M., Hand, S.J., and Godthelp, H. 2012. The rise of Australian marsupials: a synopsis of biostratigraphic, phylogenetic, palaeoecologic and palaeobiogeographic understanding. In Talent, J.A., (ed.), Earth and Life: Global Biodiversity, Extinction Intervals and Biogeographic Perturbations Through Time. Dordrecht: Springer. pp. 983-1078.

Campbell, C.R. 1976. Tertiary Dasyuridae and Peramelidae (Marsupialia) from the Tirari Desert, South Australia. Unpublished PhD Thesis, University of California, Berkeley, USA.

Case, J. A. 2001. Turnover of bandicoots in the OligoMiocene of South Australia. Journal of Vertebrate Paleontology, 21:39A.

dos Reis, M., Inoue, J., Hasegawa, M., Asher, R.J., Donoghue, P.C.J., and Yang, Z. 2012.

Phylogenomic datasets provide both precision and accuracy in estimating the timescale of placental mammal phylogeny. Proceedings of the Royal Society $B, 279: 3491-3500$.

Eriksson, T. 2001. AutoDecay ver. 5.0. Bergius Foundation, Royal Swedish Academy of Sciences, Stockholm.

Gurovich, Y., Travouillon, K.J., Beck, R.M.D., Muirhead, J., and Archer, M. 2013. Biogeographical implications of a new mouse-sized fossil bandicoot (Marsupialia: Peramelemorphia) occupying a dasyurid-like ecological niche across Australia. Journal of Systematic Paleontology, DOI:10.1080/14772019.2013. 776646. 
Hocknull, S.A. 2005. Ecological succession during the late Cainozoic of central eastern Queensland: extinction of a diverse rainforest community. Memoirs of the Queensland Museum, 51:39-122.

Hocknull, S.A., Zhao, J.-x., Feng, Y.-x., and Webb, G.E. 2007. Responses of Quaternary rainforest vertebrates to climate change in Australia.Earth and Planetary Science Letters, 264: 317-331.

Kirsch, J.A.W. 1968. Prodromus of the comparative serology of Marsupialia. Nature, 217:418-420.

Krajewski, C., Torunsky, R., Sipiorski, J.T., and Westerman, M. 2007. Phylogenetic relationships of the dasyurid marsupial genus Murexia. Journal of Mammalogy, 88:696-705.

Lewis, P.O. 2001. A likelihood approach to inferring phylogeny from discrete morphological characters. Systematic Biology, 50:913-925.

Luckett, W.P. 1993. An ontogenetic assessment of dental homologies in therian mammals, p. 182-204. In Szalay, F.S., Novacek, M.J., and McKenna, M.C. (eds.), Mammal Phylogeny: Mesozoic Differentiation, Multituberculates, Monotremes, Early Eutherians and Marsupials. Springer-Verlag, New York.

Meredith, R.W., Westerman, M., and Springer, M.S. 2008. A timescale and phylogeny for "Bandicoots" (Peramelemorphia: Marsupialia) based on sequences for five nuclear genes. Molecular Phylogenetics and Evolution, 47:1-20.

Meredith, R.W., Krajewski, C., Westerman, M., and Springer, M.S. 2009. Relationships and divergence times among the orders and families of Marsupialia. Museum of Northern Arizona Bulletin, 65:383-406.

Meredith, R.W., Janecka, J.E., Gatesy, J., Ryder, O.A., Fisher, C.A., Teeling, E.C., Goodbla, A., Eizirik, E., Simao, T.L.L., Stadler, T., Rabosky, D.L., Honeycutt, R.L., Flynn, J.J., Ingram, C.M., Steiner, C., Williams, T.L., Robinson, T.J., Burk-Herrick, A., Westerman, M., Ayoub, N.A., Springer, M.S., and Murphy, W.J. 2011. Impacts of the Cretaceous terrestrial revolution and $\mathrm{KPg}$ extinction on mammal diversification. Science, 334:521-524.

Metzger, C.A. and Retallack, G.J. 2010. Paleosol record of Neogene climate change in the Australian outback. Australian Journal of Earth Sciences, 57:871885.

Muirhead, J. 1994. Systematics, evolution and palaeobiology of recent and fossil bandicoots (Peramelemorphia, Marsupialia). Unpublished PhD Thesis, University of New South Wales, Sydney, Australia.

Muirhead, J. 2000. Yaraloidea (Marsupialia, Peramelemorphia), a new superfamily of marsupial and a description and analysis of the cranium of the Miocene Yarala burchfieldi. Journal of Paleontology, 74:512-523.
Muirhead, J. and Filan, S.L. 1995. Yarala burchfieldi, a plesiomorphic bandicoot (Marsupialia, Peramelemorphia) from Oligo-Miocene deposits of Riversleigh, northwestern Queensland. Journal of Paleontology, 69:127-134.

Muirhead, J., Dawson, L., and Archer, M. 1997. Perameles bowensis, a new species of Perameles (Peramelomorphia, Marsupialia) from Pliocene faunas of Bow and Wellington caves, New South Wales. Proceedings of the Linnean Society of New South Wales, 17:163-174

Murray, P. and Megirian, D. 1992. Continuity and contrast in middle and late Miocene vertebrate communities from Northern Territory, p. 195-218. In Murray, P.F. and Megirian, D. (eds.), Proceedings of the 1991 Conference on Australasian Vertebrate Evolution, Palaeontology and Systematics, The Beagle, Records of the Northern Territory Museum of Arts and Sciences, Alice Springs, Australia.

Myers, T.J. 2001. Prediction of marsupial body mass. Australian Journal of Zoology, 49:99-118.

Myers, T.J., Crosby, K., Archer, M., and Tyler, M. 2001. The Encore local Fauna, a late Miocene assemblage from Riversleigh, northwestern Queensland. Memoirs of the Association of Australasian Palaeontologists, 25:147-154.

Nilsson, M.A., Arnasson, U., Spencer, P.B.S., and Janke, A. 2004. Marsupial relationships and a timeline for marsupial radiation in South Gondwana. Gene, 340:189-196.

Price, G.J. 2002. Perameles sobbei, sp. nov. (Marsupialia, Peramelidae), a Pleistocene bandicoot from the Darling Downs, south-eastern Queensland. Memoirs of the Queensland Museum, 48:193-197.

Price, G. J. 2005. Fossil bandicoots (Marsupialia, Peramelidae) and environmental change during the Pleistocene on the Darling Downs, southeastern Queensland, Australia. Journal of Systematic Palaeontology, 4:347-356.

Quarles van Ufford, A. and Cloos, M. 2005. Cenozoic tectonics of New Guinea. American Association of Petroleum Geologists Bulletin, 89:119-140.

Raterman, D., Meredith, R.W., Reudas, L.A., and Springer, M.S. 2006. Phylogenetic

relationships of the cuscuses and brushtail possums (Marsupialia:

Phalangeridae) using the nuclear gene BRCA1. Australian Journal of Zoology, 54:353-361.

Schwartz, L.R.S. 2006. A new species of bandicoot from the Oligocene of Northern Australia and implications of bandicoots for correlating Australian Tertiary mammal faunas. Palaeontology, 49:991-998.

Stirton, R.A. 1955. Late Tertiary marsupials from South Australia. Records of the South Australian Museum, 11:247-268.

Swofford, D. L. 2002. PAUP*. Phylogenetic Analysis Using Parsimony ( ${ }^{*}$ and Other Methods). Version 4 (updated to 10 beta). Sinauer Associates, Sunderland, Massachussets. 
Travouillon, K.J., Gurovich, Y., Beck, R.M.D., and Muirhead, J. 2010. An exceptionally well-preserved shortsnouted bandicoot (Marsupialia; Peramelemorphia) from Riversleigh's Oligo-Miocene deposits, northwestern Queensland, Australia. Journal of Vertebrate Paleontology, 30:1528-1546.

Travouillon, K.J., Legendre, L., Archer, M., and Hand, S. 2009. Palaeoecological analyses of Riversleigh's Oligo-Miocene sites: Implications for Oligo-Miocene climate change in Australia. Palaeogeography, Palaeoclimatology, Palaeoecology, 276:24-37.

Travouillon, K.J., Gurovich, Y., Archer, M., Hand, S.J., and Muirhead, J., 2013. The genus Galadi: three new bandicoots (Marsupialia; Peramelemorphia) from Riversleigh's Miocene deposits, north-western Queensland, Australia. Journal of Vertebrate Paleontology, 33:153-168.

Turnbull, W.D., Lundelius, E.L.Jr., and Archer, M. 2003. Dasyurids, perameloids, phalangeroids, and vombatoids from the early Pliocene Hamilton fauna, Victoria, Australia. Bulletin of the American Museum of Natural History, 279:513-540.

Westerman, M., Young, J., and Krajewski, C. 2008. Molecular relationships of Pseudantechinus, Parantechinus, and Dasykaluta (Marsupialia: Dasyuridae). Australian Mammalogy, 29:201-212.
Westerman, M., Kear, B.P., Aplin, K., Meredith, R.W., Emerling, C., and Springer, M.S. 2012. Phylogenetic relationships of living and recently extinct bandicoots based on nuclear and mitochondrial DNA sequences. Molecular Phylogenetics and Evolution, 62:97-108.

Wilson, D.E. and Reeder D.M. 2005. Mammal Species of the World. A Taxonomic and Geographic Reference (third edition), Johns Hopkins University Press, Baltimore, USA.

Woodburne, M.O. and Case, J.A. 1996. Dispersal, vicariance, and the late Cretaceous to early Tertiary land mammal biogeography from South America to Australia. Journal of Mammalian Evolution, 3:121-162.

Woodburne, M.O., Macfadden, B.J., Case, J.A., Springer, M.S., Pledge, N., Power, J.D.,

Woodburne, J., and Springer, K.B. 1993. Land mammal biostratigraphy and magnetostratigraphy of the Etadunna Formation (late Oligocene) of South Australia. Journal of Vertebrate Paleontology, 13:483-515.

Worthy, T.H., Tennyson, A.J.D., Archer, M., Musser, A.M., and Hand, S.J. 2006. Miocene mammal reveals a Mesozoic ghost lineage on insular New Zealand, southwest Pacific. Proceedings of the National Academy of Sciences of the United States of America, 103:19419-19423. 


\section{APPENDIX 1}

List and description of 156 characters and states used in our phylogenetic analyses. Ordered characters are indicated with an asterisk $\left({ }^{*}\right)$.

1. Upper incisor number

(0) five incisors present

(1) four incisors present (I5 lost)

2. Diastema between 14 and 15

(0) absent

(1) present

3. 15 morphology

(0) I5 similar in morphology to I1-4

(1) I5 pointed and strongly canine-like

(2) 15 premolar like,

4. *Degree of development of lingual shelf on

P3

(0) no shelf

(1) small/weakly developed shelf

(2) well-developed lingual shelf

(3) well-developed lingual shelf that

extends to the buccal side of $\mathrm{P} 3$,

5. *P3 major cusp development

(0) P3 major cusp laterally compressed

(1) P3 major cusp laterally enlarged but not conical

(2) P3 major cusp large and conical, but

$\mathrm{P} 3$ is narrower than M1

(3) P3 Major cusp large and conical, and

$\mathrm{P} 3$ is wider than $\mathrm{M} 1$,

6. *Stylar crest on M1

(0)stylar crest present on StD connects to metastylar tip

(1) StD is a conical cusp not connected to the stylar crest running to the metastylar tip

(2) StD is a conical cusp and no stylar crest present,

7. *Anterior cingulum of M1

(0) no anterior cingulum

(1) small anterior cingulum lingual to anterior tip of tooth, no connection to talon

(2) anterior cingulum enlarged and

connects to talon as small shelf,

8. *Anterior cingulum of M3

(0) no anterior cingulum
(1) small anterior cingulum lingual to anterior tip of tooth

(2) small anterior cingulum connected to protocone shelf by a small shelf

(3) large anterior cingulum expanded further up to the protocone,

9. *Direction of preparacrista of M1

(0) preparacrista anterobuccally orientated to connect to anteriorly positioned StB.

(1) preparacrista buccally orientated (perpendicular to tooth row) then posterobuccally orientated

(2) preparacrista posterobuccally orientated to connect to posteriorly located StB

(3) preparacrista posterobuccally orientated to connect to StB and then reconnects with postparacrista posteriorly,

10. *Posterior cingulum of $\mathrm{M} 3$

(0) absent

(1) present

(2) present and wide,

11. *Morphology of the centrocrista on M1 and $\mathrm{M} 2$

(0) postparacrista and premetacrista contact each other, forming a complete centrocrista that connects the paracone and metacone (more lingually).

(1) postparacrista and premetacrista contact each other, forming a complete centrocrista that connects the paracone and metacone (more buccally)

(2) postparacrista does not connect to the premetacrista and ends at the base of StB, premetacrista ends at base of StD ,

12. *Morphology of centrocrista on M3

(0) postparacrista and premetacrista contact each other, forming a complete centrocrista that connects the paracone and metacone (more lingually).

(1) postparacrista and premetacrista contact each other, forming a complete centrocrista that connects the paracone and metacone (more buccally) 
(2) postparacrista does not connect to the premetacrista and ends at the base of StB, premetacrista ends at base of StD ,

13. *Lobation of i3

(0) i3 is unicuspid

(1) i3 posterior cusp present but small

(2) I3 posterior cusp present and large,

14. Length of $p 3$

(0) p3 longer or equal in length to p2

(1) p3 shorter than p2,

15. Presence of preentocristid

(0) present

(1) absent,

16. Direction of preentocristid of $\mathrm{m} 1-3$

(0) anteroposterior

(1) oblique,

17. Cusp within the hypoflexid region, between the talonid and trigonid on the buccal side

(0) no median buccal cusp present

(1) median buccal cusp present ,

18. Distinction between lower molar crowns and roots

(0) crown distinct from roots

(1) crown and root indistinct (other than for limit of enamel)

19. Hypoconulid posterior to entoconid

(0) hypoconulid positioned posterobuccal to the entoconid

(1) hypoconulid positioned almost directly posterior to the entoconid,

20. *Size of talonid on $\mathrm{m} 4$

(0) entoconid and hypoconid large, talonid relatively wide, crests clearly identifiable.

(1) entoconid and hypoconid smaller than in state 0 , talonid smaller

(2) further reduction of entoconid and hypoconid, talonid very small, crest poorly defined,

21. Snout length and premaxilla size

(0) premaxilla taller than it is long; maxillanasal contact longer than premaxilla-nasal contact (usually correlated with a relatively short snout)

(1) premaxilla longer than it is tall; premaxilla-nasal contact longer than maxilla-nasal contact (usually correlated with a relatively elongate snout),
22. Width of nasals

(0) broad nasals

(1) slender nasals, not markedly expanded posteriorly ,

23. *Position of nasal-frontal suture/maximum posterior extension of nasals

(0) posterior to the anterior rim of the orbit when viewed laterally

(1) nasals terminate just anterior to the orbit when viewed laterally (associated with a wide maxilla-frontal suture)

(0) nasals terminate well anterior to the anterior margin of the orbit,

24. Infraorbital canal length

(0) long infraorbital canal (longer than half the molar row).

(1) short infraorbital canal (shorter or equal to half the molar row).,

25. Jugal-maxilla contact

(0) jugal invades the maxilla and extends onto the facial region of the skull (not bifid)

(1) maxilla invades the zygomatic arch so that the jugal has two thin wings around the posterior maxillary flange (bifid),

26. *Lacrimal orbital rim

(0) lacrimal crest absent

(1) partially developed lacrimal crest

(2) fully developed lacrimal crest,

27. *Antorbital fossa

(0) antorbital fossa absent

(1) weak or partial fossa development

(2) very deep antorbital fossa,

28. *Orbitosphenoid

(0) orbitosphenoid identifiable in lateral view as a large ossification

(1) orbitosphenoid identifiable in lateral view as a small ossification

(2) orbitosphenoid is very small or absent and not obvious in lateral view,

29. Alisphenoid

(0) alisphenoid-parietal contact

(1) squamosal-frontal contact ,

30. *Sphenorbital fissure and foramen

rotundum

(0) sphenorbital fissure slightly larger than foramen rotundum. Both canals are tube- 
like in shape, especially the foramen rotundum

(1) sphenorbital fissure is enlarged and more widely open, and there is a reduction in the length of the tube leading to the foramen rotundum

(2) sphenorbital fissure is further enlarged and open, and there is no tube leading to the foramen rotundum, which instead appears,

31. Presence of Accessory fenestrae

(0) absent

(1) present,

32. Presence of dividing septa in maxillopalatine fenestrae

(0) septum present in maxillopalatine fenestrae

(1) septum absent in maxillopalatine fenestrae,

33. Postglenoid foramen

(0) foramen bound by squamosal or squamosal and alisphenoid

(1) foramen bounded medially by the petrosal,

34. Morphology of the primary foramen ovale

(0) primary foramen ovale is between alisphenoid and petrosal

(1) primary foramen ovale is entirely within the alisphenoid,

35. *Morphology of the secondary foramen ovale

(0) secondary foramen ovale absent

(1) secondary foramen ovale defined by a complete strut or bridge formed by the alisphenoid, but the primary foramen ovale is still visible

(2) secondary foramen ovale present, and extensive ossification of the alisphenoid means that the primary foramen ovale is no longer visible in intact skulls,

36. *Morphology of the ectotympanic

(0) thin

(1) somewhat thickened

(2) further thickened

(3) heavily thickened,

37. *Degree of inflation of the alisphenoid tympanic process
(0) alisphenoid tympanic process small, lateral and medial walls open.

(1) alisphenoid tympanic process largely open but medial wall enclosed greater than in state 0 , and hypotympanic sinus is also enlarged relative to state 0

(2) alisphenoid tympanic process and hypotympanic sinus further enlarged.relative to state 1 ; hypotympanic sinus walled posteriorly by the alisphenoid (3) alisphenoid tympanic process and hypotympanic sinus greatly hypertrophied,

38. Alisphenoid tympanic process shape

(0) flattened

(1) ventrally rounded, anterior boundary rounded does not extend as far as the transverse foramen or foramen ovale (2) ventrally rounded, anterior boundary pointed and extends as far as the transverse foramen

(3) ventrally angular, anterior boundary pointed and terminates anterior to the transverse foramen,

39. *Morphology of the rostral tympanic process of the petrosal (0)rostral tympanic process of the petrosal absent or very small

(1) rostral tympanic process of the petrosal forms a distinct projecting process that partially walls the posteromedial margin of the hypotympanic sinus .

(2) rostral tympanic process of the petrosal further enlarged, forming elongate crestlike process that extends the length of the promontorium and forms posteromedial wall of the hypotympanic sinus; medial margin of petrosal overlaps basioccipital. (3) ventral margin of the rostral tympanic process of the petrosal extends laterally and slightly dorsally, resulting in the formation of a distinct hypotympanic sinus within the rostral tympanic process itself (4) dorsal extention of the ventral margin of the rostral tympanic process relative to state 3 , resulting in lateral wall to the hypotympanic sinus within the process 40. Epitympanic recess 
(0) poorly defined and shallow

(1) wider and deeper than the plesiomorphic state but still relatively poorly defined

(2) deep sinus with enclosing walls that is well distinguished from remainder of auditory cavity

(3) wide and deep sinus that extends posterolaterally,

41. Squamosal epitympanic sinus
(1) absent
(2) present, poorly defined
(3) wide with high posterior wall
(4) deep and round,

42. Supraoccipital shape

(0) supraoccipital about as tall as it is wide

(1) supraoccipital taller than it is wide,

43. Postorbital processes

(0) absent or indistinct

(1) present,

44. Left and right parietal suture

(0) median suture present

(1) partially or completely co-ossified suture,

45. *Sagittal crest
(0) no sagittal crest
(1) sagittal crest small, not extending to frontals
(0) sagittal crest large and extending to frontals,

46. Interparietal

(0) absent

(1) present,

47. Lambdoid sesamoids
(0) absent
(1) present,

48. *Number of mental foramen

(0) one mental foramen

(1) two mental foramina

(2) three or more mental foramina,

49. Shape of I1

(0) styliform or chisellike

(1) mesiodistally expanded and flatcrowned,

50. Upper canine alveolus

(0) occupies premaxillary-maxillary suture

(1) entirely contained within maxillary,
51. *Relative height of $\mathrm{P} 2$ and $\mathrm{P} 3$
(0) P2 taller than P3
(1) P2 and P3 subequal in height
(2) P3 taller than P2,

52. Posterior crest of $\mathrm{P} 3$

(0) well-developed posterior cutting edge

(1) lacking posterior cutting edge,

53. *Relative height of $p 2$ and $p 3$

(0) p2 taller than p3

(1) p2 and p3 subequal in height

(2) p3 taller than $p 2$,

54. Hypoconulid notch

(0) present in anterior cingulum of $\mathrm{m} 2-4$

(1) absent,

55. *Relative position of hypoconid to protoconid on $\mathrm{m} 3$

(0) buccally salient to protoconid

(1) subequal to protoconid

(2) lingual to salient protoconid,

56. Posterior cingulid

(0) absent

(1) present,

57. Shape of narial flange of premaxilla

(0) no distinct process

(1) wing-like narial processes present,

58. Position of lacrimal foramen

(0) within lacrimal

(1) within lacrimal-maxillary suture,

59. Supraoccipital contribution to foramen magnum

(0) contributes to superior margin of foramen magnum

(1) exoccipitals contact each other medially, excluding the supraoccipital from the foramen magnum ,

60. Shape of I2-4

(0) rhomboidal crowns

(1) mesiodistally expanded and flatcrowned,

61. Shape of upper canine

(0) single-rooted unicuspid upper canine

(1) accessory cusps are present on either side of the major cusp of $\mathrm{C} 1$,

62. Lower molar crown height

(0) lower molars are as high on the buccal side as they are on the lingual side 
(1) lower molar height is significantly higher on buccal side than lingual side,

63. Position of the metacone

(0) metacone is directly posterior to the paracone

(1) metacone is shifted lingually in relation to the paracone,

64. Size of 13

(0) I2-4 are the same size

(1) I3 is larger than I2 and I4,

65. Lingual cusp presence on lower incisors

(0) present

(1) absent,

66. Diastema between i3 and canine (0) no diastema

(1) diastema present,

67. Shape of lower canine

(0) single-rooted unicuspid lower canine

(1) accessory cusps are present on either side of the major cusp of $c 1$,

68. Size of upper or lower canine

(0) large, raised above premolars

(1) small, about as high as premolars,

69. *Diastema between $\mathrm{C} 1$ and P1

(0) no diastema

(1) short, less than the length of P1

(0) long, more than the length of $\mathrm{P} 1$,

70. *Length of $\mathrm{P} 1$

(0) P1 is shorter than P2

(1) P1 is as long as P2

(2) $\mathrm{P} 1$ is longer than $\mathrm{P} 2$,

71. Anterior cusp of $\mathrm{P} 1$ and/or $\mathrm{P} 2$

(0) tall distinct cusp

(1) small remnant or no cusp,

72. *Diastema between $\mathrm{P} 1$ and $\mathrm{P} 2$

(0) no diastema

(1) short, less than the length of $p 1$

(2) long, more than the length of $p 1$,

73. Morphology of the central cusp of $\mathrm{P} 1$ and $\mathrm{P} 2$

(0) central cusp is not inflated

(1) central cusp is inflated widening the tooth anteriorly,

74. *Relative length of P2 and P3

(0) P3 almost twice as long as P2

(1) P2 shorter than P3
(2) P2 and P3 subequal length

(3) P2 longer than P3

(4) P2 twice as long as P3,

75. *Diastema between canine and $\mathrm{p} 1$

(0) no diastemata

(1) short, less than the length of $p 1$

(2) long, more than the length of $p 1$,

76. Length of $\mathrm{p} 1$

(0) $p 1$ is shorter than either $p 2$ or $p 3$

(1) p1 is as long as p2 or p3,

77. Anterior cusp of $\mathrm{p} 1$

(0) tall distinct cusp

(1) none or small remnant,

78. Anterior cusp of $\mathrm{p} 2$

(0) tall distinct cusp

(1) none or small remnant,

79. *Diastema between $\mathrm{p} 1$ and $\mathrm{p} 2$

(0) no diastemata

(1) short, less than the length of $p 1$

(2) long, more than the length of $p 1$,

80. *Relative length of $p 2$ and $p 3$

(0) p3 almost twice as long as p2

(1) p2 shorter than $p 3$

(2) p2 and p3 subequal length

(3) p2 longer than P3,

81. Anterior cusp of $p 3$

(0) tall distinct cusp

(1) none or small remnant,

82. p3 major cusp development

(0) p3 major cusp laterally compressed

(1) p3 major cusp very large,

83. Reclining of $p 3$

(0) the anterior and posterior roots of p3 are level

(1) the anterior root of p3 is more exposed than the posterior root, reclining p3 toward $\mathrm{m} 1$,

84. *Size of StA on M1

(0) StA is large, with a long crest running anteroposteriorly

(1) StA is small, with a short or no crest running anteroposteriorly

(2) StA remnant or no StA,

85. Morphology of $S t B / S t C$ on $M 1$

(0) no StC or B

(1) StB and StC are distinct cusps 
(2) StB and StC are fused and oval in shape connected by a stylar crest but clearly identifiable as separate cusp

(3) StB and StC are fused and oval in shape connected by a stylar crest but difficult to clearly identify each cusp,

86. *Relative size of StB and StC on M1

(0) StB larger than StC

(1) StB subequal to StC

(2) StC larger than StB,

87. Connection of StB and StD on M1

(0) StB/C and StD are connected by a series of crests

(1) StB/C and StD are not connected by any crests,

88. *Posterior cingulum of M1

(0) absent

(1) present

(2) present and wide,

89. *Termination of postprotocrista on M1

(0) postprotocrista ends on anterior flank of metacone

(1) postprotocrista ends on lingual flank of metacone

(2) postprotocrista ends on posterolingual flank of metacone

(3) postprotocrista joins with the posterior cingulum and ends posteriorly to the midpoint of the postmetacrista

(4) postprotocrista joins with the posterior cingulum and ends at the lingual flank of the metastylar tip,

90. *Position of metaconule on M1

(0) metaconule is directly positioned at the base of the metacone

(1) a small shelf is between the base of the metacone and the metaconule

(2) a larger shelf is between the base of the metacone and the metaconule,

91. StD1 on M1

(0) present

(1) absent,

92. *StE on M1

(0) StE present as a distinct cusp

(1) remnant of StE as a stylar crest or

small cusp

(2) no StE (no stylar crest),
93. *Anterior cingulum of M2

(0) no anterior cingulum

(1) small anterior cingulum lingual to anterior tip of tooth

(2) small anterior cingulum connected to protocone shelf by a small shelf

(3) large anterior cingulum expanded further up to the protocone,

94. * Size of StA on M2

(0) StA is large, with a long crest running anteroposteriorly

(1) StA is small, with a short or no crest running anteroposteriorly

(2) no StA,

95. Morphology of StB on M2

(0) StB is oval with a stylar crest running through it

(1) StB is conical with no stylar crest connection,

96. Connection of $\mathrm{StB}$ and $\mathrm{StD}$ on $\mathrm{M} 2$

(0) StB and StD are connected by a series of crests

(1) StB and StD are not connected by any crests,

97. *Direction of preparacrista of M2

(0) preparacrista terminates at base of StB (no crest connection).

(1) preparacrista terminates at the tip StB.

(2) preparacrista connects to StB with a weak connection to StA

(3) preparacrista connects to parastylar tip/ StA,

98. *Stylar crest on M2

(0) stylar crest present on StD connects to metastylar tip

(1) StD is a conical cusp not connected to the stylar crest running to the metastylar tip

(2) StD is a conical cusp and no stylar crest present,

99. *Posterior cingulum of M2

(0) absent

(1) present

(2) present and wide,

100. * Termination of postprotocrista on M2

(0) postprotocrista ends on anterior flank of metacone 
(1) postprotocrista ends on lingual flank of metacone

(2) postprotocrista ends on posterolingual flank of metacone

(3) postprotocrista joins with the posterior cingulum and ends posteriorly to the midpoint of the postmetacrista

(4) postprotocrista joins with the posterior cingulum and ends at the lingual flank of the metastylar tip,

101. *Position of metaconule on M2

(0) metaconule is directly positioned at the base of the metacone

(1) a small shelf is between the base of the metacone and the metaconule

(2) a larger shelf is between the base of the metacone and the metaconule,

102. * $\mathrm{StC}$ on $\mathrm{M} 2$

(0) present as tall cusp

(1) small remnant present

(2) absent,

103. StD1 on M2

(0) present

(1) absent,

104. *StE on M2

(0) StE present as a distinct cusp

(1) remnant of StE as a stylar crest

(2) no StE (no stylar crest),

105. * Size of StA on M3

(0) StA is large, with a long crest running anteroposteriorly

(1) StA is small, with a short or no crest

running anteroposteriorly

(2) no St,

106. Morphology of StB on M3

(0) StB is oval with a stylar crest running through it

(1) StB is conical with no stylar crest connection (except by wear),

107. Connection of StB and StD on M3

(0) StB and StD are connected by a series of crests

(1) StB and StD are not connected by any crests,

108. *Direction of preparacrista of M3

(0) preparacrista terminates at base of StB (no crest connection).
(1) preparacrista terminates at the tip StB.

(2) preparacrista connects a crest linking

StA and StB

(3) preparacrista connects to parastylar tip/ StA,

109. *Stylar crest on M3

(0) stylar crest present on StD connects to metastylar tip

(1) StD is a conical cusp not connected to the stylar crest running to the metastylar tip

(2) StD is a conical cusp and no stylar crest present,

110. *Termination of postprotocrista/ posthypocrista on M3

(0) postprotocrista ends on anterior flank of metacone

(1) postprotocrista ends on lingual flank of metacone

(2) postprotocrista ends on posterolingual flank of metacone

(3) postprotocrista joins with the posterior cingulum and ends posteriorly to the midpoint of the postmetacrista

(4) postprotocrista joins with the posterior cingulum and ends at the lingual flank of the metastylar tip,

111. *Position of metaconule on M3

(0) metaconule is directly positioned at the base of the metacone

(1) a small shelf is between the base of the metacone and the metaconule

(2) a larger shelf is between the base of the metacone and the metaconule,

112. * $\mathrm{StC}$ on $\mathrm{M} 3$

(0) present as tall cusp

(1) small remnant present

(2) absent,

113. StD1 on M3

(0) present

(1) absent,

114. *StE on M3

(0) StE present as a distinct cusp

(1) remnant of StE as a stylar crest

(2) no StE (no stylar crest),

115. *Anterior cingulum of M4

(0) no anterior cingulum 
(1) small anterior cingulum lingual to anterior tip of tooth

(2) small anterior cingulum connected to protocone shelf by a small shelf

(3) large anterior cingulum expanded further up to the protocone,

116. *StB on M4

(0) no StB

(1) small StB

(2) Large StB,

117. Connection of StA and StB on M4

(0) no connection

(1) crest connecting the two cusps,

118. Direction of preparacrista of M4

(0) preparacrista terminates StA

(1) preparacrista terminates at the anterior flank of StB,

119. Postparacrista of M4

(0) postparacrista straight

(1) postparacrista curves as a small centrocrista and ends just after the centrocrista,

120. *Termination of postprotocrista on M4

(0) postprotocrista ends anterior to the most posterior end of the postparacrista (1) postprotocrista ends level with the most posterior end of the postparacrista

(2) postprotocrista ends posterior to the most posterior end of the postparacrista ,

121. *Metacone on M4

(0) absent

(1) small metacone raise above the postparacrista

(2) large metacone expands the length of the tooth,

122. StC/D on M4

(0) absent

(1) present,

123. Presence of protocone on M4

(0) present

(1) absent,

124. Anterior cingulid on $\mathrm{m} 1$

(0) absent or small remnant

(1) present,

125. Hypoflexid on $\mathrm{m} 1$

(0) absent

(1) present,
126. *Shape of trigonid on $\mathrm{m} 1$

(0) paraconid-metaconid distance is longer than metaconid-protoconid distance

(1) paraconid-metaconid distance is as long as metaconid-protoconid distance

(0) paraconid-metaconid distance is shorter than metaconid-protoconid distance

(1) paraconid highly reduced or absent, 127. Position of paraconid on $\mathrm{m} 1$

(0) paraconid anterior to metaconid

(1) paraconid anterobuccal to metaconid,

128. Shape of unworn entoconid on m1-3

(0) oval

(1) triangular (wider posteriorly than anteriorly)

(2) conical,

129. *Cristid obliqua termination on $\mathrm{m} 1$

(0) cristid obliqua terminates buccal to level with the protocone

(1) cristid obliqua terminates lingual to the protocone to the midpoint to the tooth width

(2) cristid obliqua terminates lingual to the midpoint of the tooth width,

130. Posthypocristid direction on $\mathrm{m} 1$

(0)oblique to the tooth row axis

(1) perpendicular to the tooth row axis ,

131. Connection of posthypocristid on $\mathrm{m} 1$

(0) posthypocristid connects to hypoconulid

(1) posthypocristid connects to base of entoconid when the tooth is unworn, but as the tooth wears down, a crest connects the tip of the entoconid to the posthypocristid., 132. Size of hypoconulid on $\mathrm{m} 1$

(0) large distinct cusp

(1) small cusp,

133. *Shape of trigonid on $\mathrm{m} 2$

(0) paraconid-metaconid distance is longer than metaconid-protoconid distance

(1) paraconid-metaconid distance is as long as metaconid-protoconid distance (2) paraconid-metaconid distance is shorter than metaconid-protoconid distance

(3) paraconid highly reduced or absent, 
134. *Cristid obliqua termination on $\mathrm{m} 2$

(0) cristid obliqua terminates buccal to the protocone

(1) cristid obliqua terminates lingual to the protocone about midpoint to the tooth width

(2) cristid obliqua terminates lingual to the midpoint of the tooth width,

135. Posthypocristid direction on $\mathrm{m} 2$

(0) oblique to the tooth row axis

(1) perpendicular to the tooth row axis ,

136. Connection of posthypocristid on $\mathrm{m} 2$

(0) posthypocristid connects to hypoconulid

(1) posthypocristid connects to entoconid, 137. *Size of hypoconulid on $\mathrm{m} 2$

(0) large distinct cusp

(1) small cusp

(2) hypoconulid absent,

138. *Shape of trigonid on $\mathrm{m} 3$

(0) paraconid-metaconid distance is longer than metaconid-protoconid distance

(1) paraconid-metaconid distance is as longer as metaconid-protoconid distance

(2) paraconid-metaconid distance is shorter than metaconid-protoconid distance

(3) paraconid highly reduced or absent,

139. *Cristid obliqua termination on $\mathrm{m} 3$

(0) cristid obliqua terminates buccal to the protocone

(1) cristid obliqua terminates lingual to the protocone about midpoint to the tooth width

(2) cristid obliqua terminates lingual to the midpoint of the tooth width,

140. Posthypocristid direction on $\mathrm{m} 3$

(0) oblique to the tooth row axis

(1) perpendicular to the tooth row axis ,

141. Connection of posthypocristid on $m 3$

(0) posthypocristid connects to hypoconulid

(1) posthypocristid connects to entoconid, 142. *Size of hypoconulid on $\mathrm{m} 3$

(0) large distinct cusp

(1) small cusp

(2) hypoconulid absent,
143. *Shape of trigonid on $\mathrm{m} 4$

(0) paraconid-metaconid distance is longer than metaconid-protoconid distance

(1) paraconid-metaconid distance is as longer as metaconid-protoconid distance

(2) paraconid-metaconid distance is shorter than metaconid-protoconid distance

(3) paraconid highly reduced or absent,

144. Preentocristid on $\mathrm{m} 4$

(0) present

(1) absent,

145. Preentocristid orientation on $\mathrm{m} 4$

(0) anteroposterior

(1) oblique,

146. Postentocristid on $\mathrm{m} 4$

(0) absent

(1) present,

147. Postentocristid orientation on $\mathrm{m} 4$

(0) anteroposterior

(1) oblique,

148. Cristid obliqua termination on $\mathrm{m} 4$

(0) cristid obliqua terminates lingual to the protocone about midpoint to the tooth width

(1) cristid obliqua terminates lingual to the midpoint of the tooth width,

149. *Posthypocristid direction on $\mathrm{m} 4$

(0) oblique to the tooth row axis

(1) perpendicular to the tooth row axis

(2) anteriorly orientated,

150. * Size of entoconid

(0) large distinct cusp

(1) small cusp

(2) entoconid absent,

151. *Size of hypoconulid on $\mathrm{m} 4$

(0) large distinct cusp

(1) small cusp

(2) hypoconulid absent, 152. Buccal shelf on $\mathrm{m} 4$

(0) buccal shelf end at buccal side of hypoconid

(1) buccal shelf buccally reduced (hypoconid more buccal than shelf), 153. Presence of $P 3$

(0) present

(1) absent, 
154. Presence of $p 3$

(0) present

(1) absent,

155. Presence of palatine fenestrae

(0) absent
(1) present, 156. Presence of maxillary fenestrae

(0) absent

(1) present, 
TRAVOUILLON ET AL: OLIGOCENE BANDICOOT

\section{APPENDIX 2}

Nexus-formatted character matrix for the 42 taxa included in our phylogenetic analyses.

Outgroup taxa were Djarthia murgonensis, Barinya wangala, Mutpuracinus archibaldi,

Dasyurus hallucatus, Dasyuroides byrnei, Phascogale tapoatafa, Antechinus stuartii,

Sminthopsis macroura. ? = missing data; - = inapplicable.

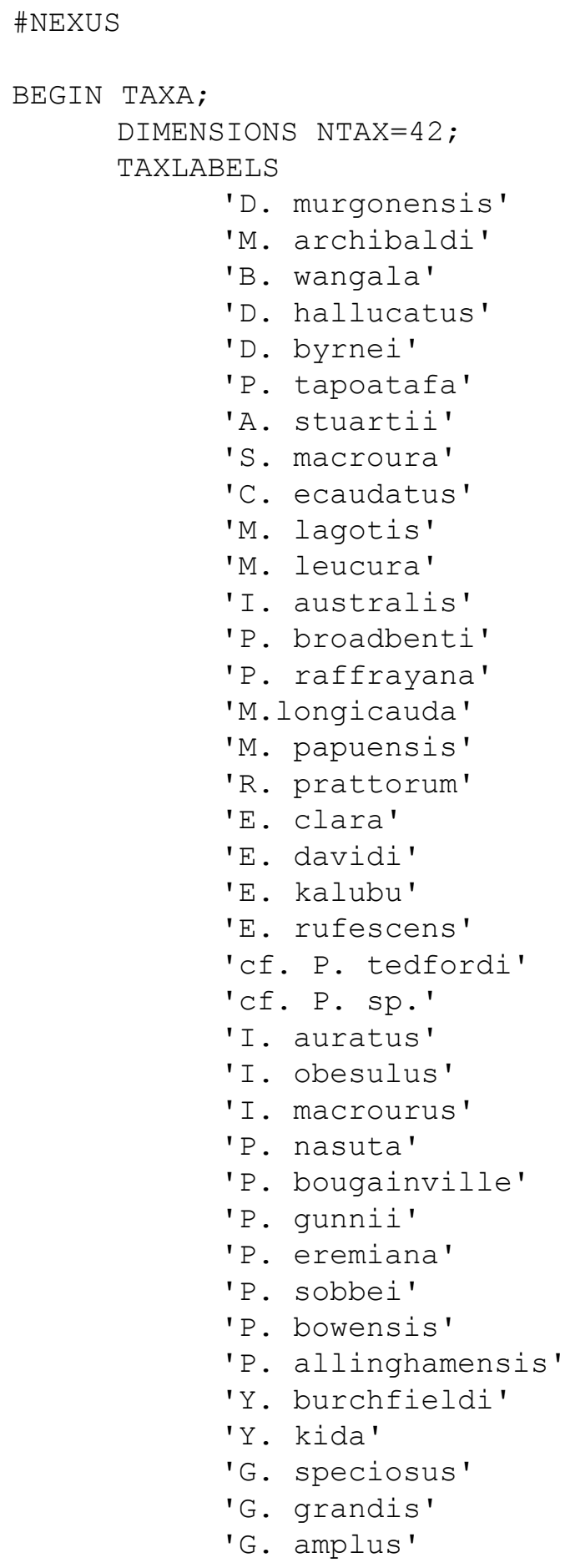




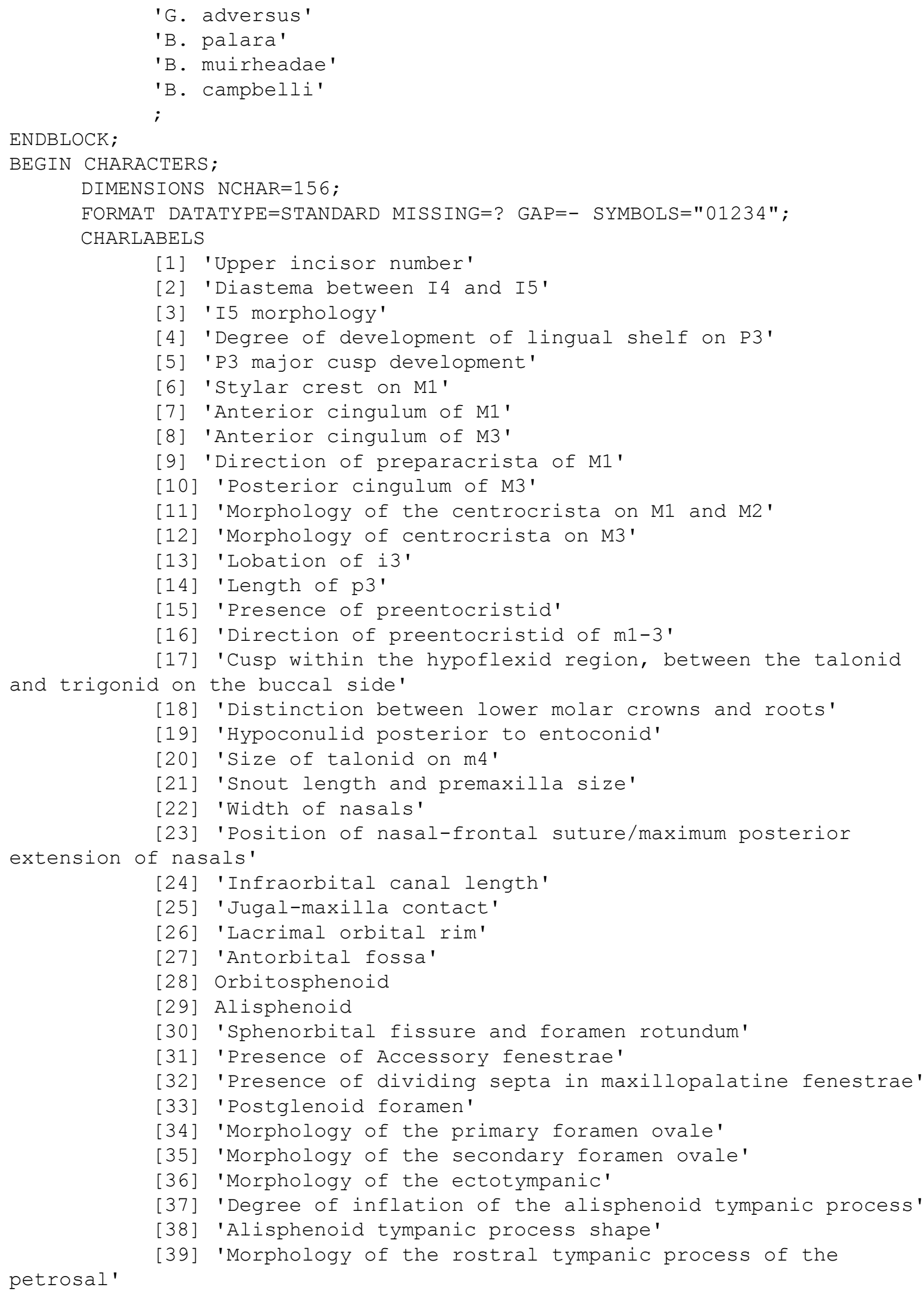




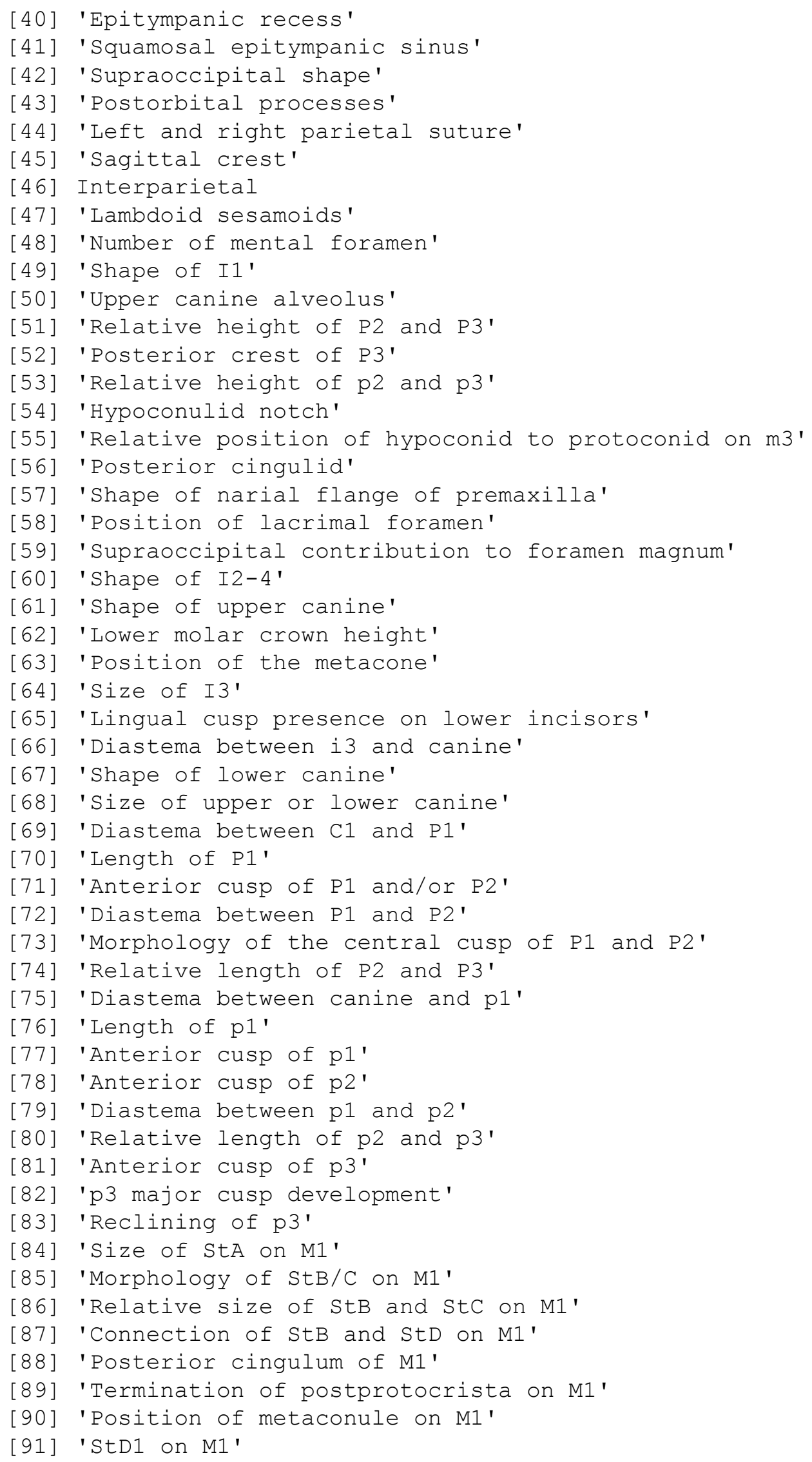




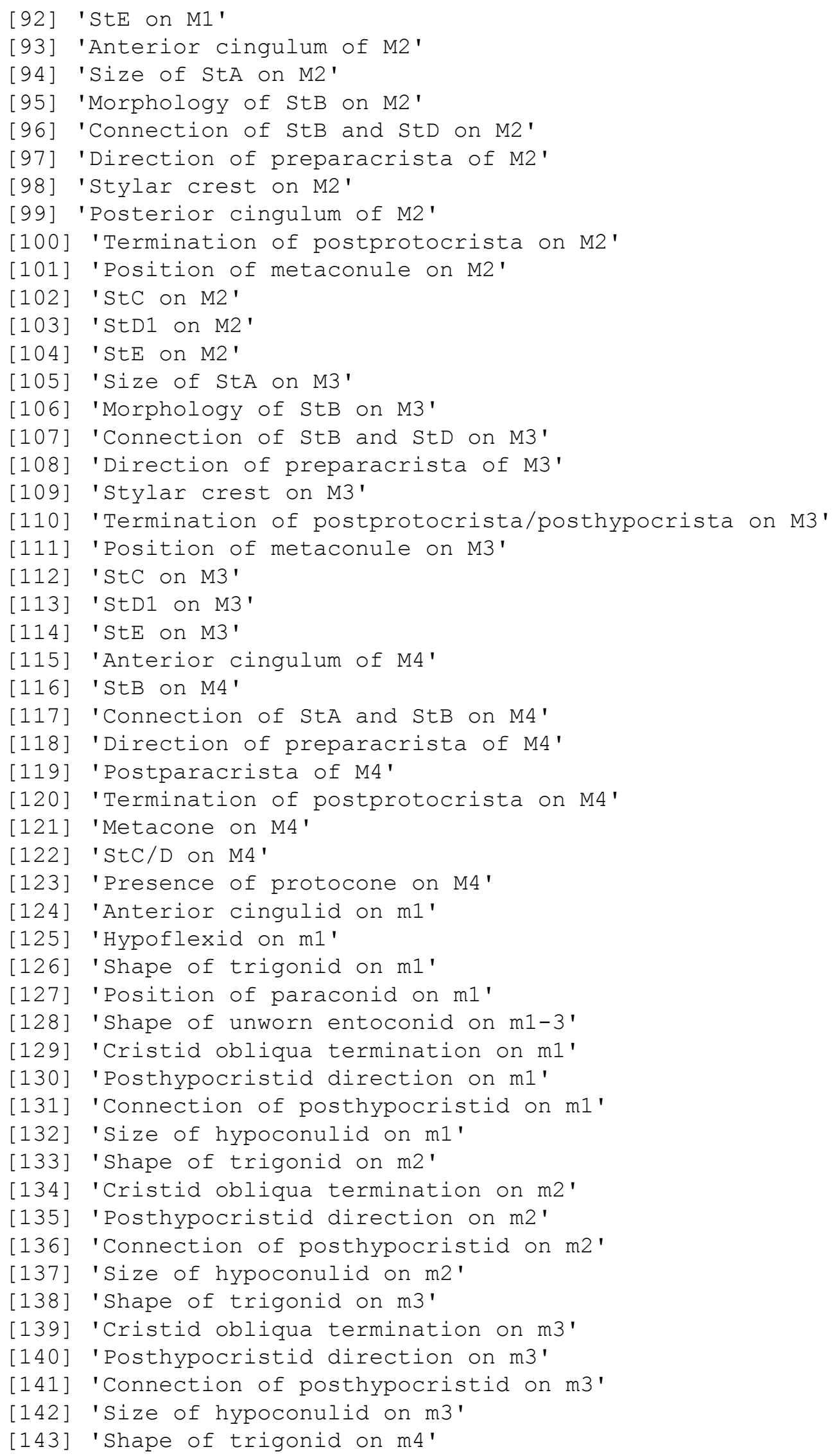




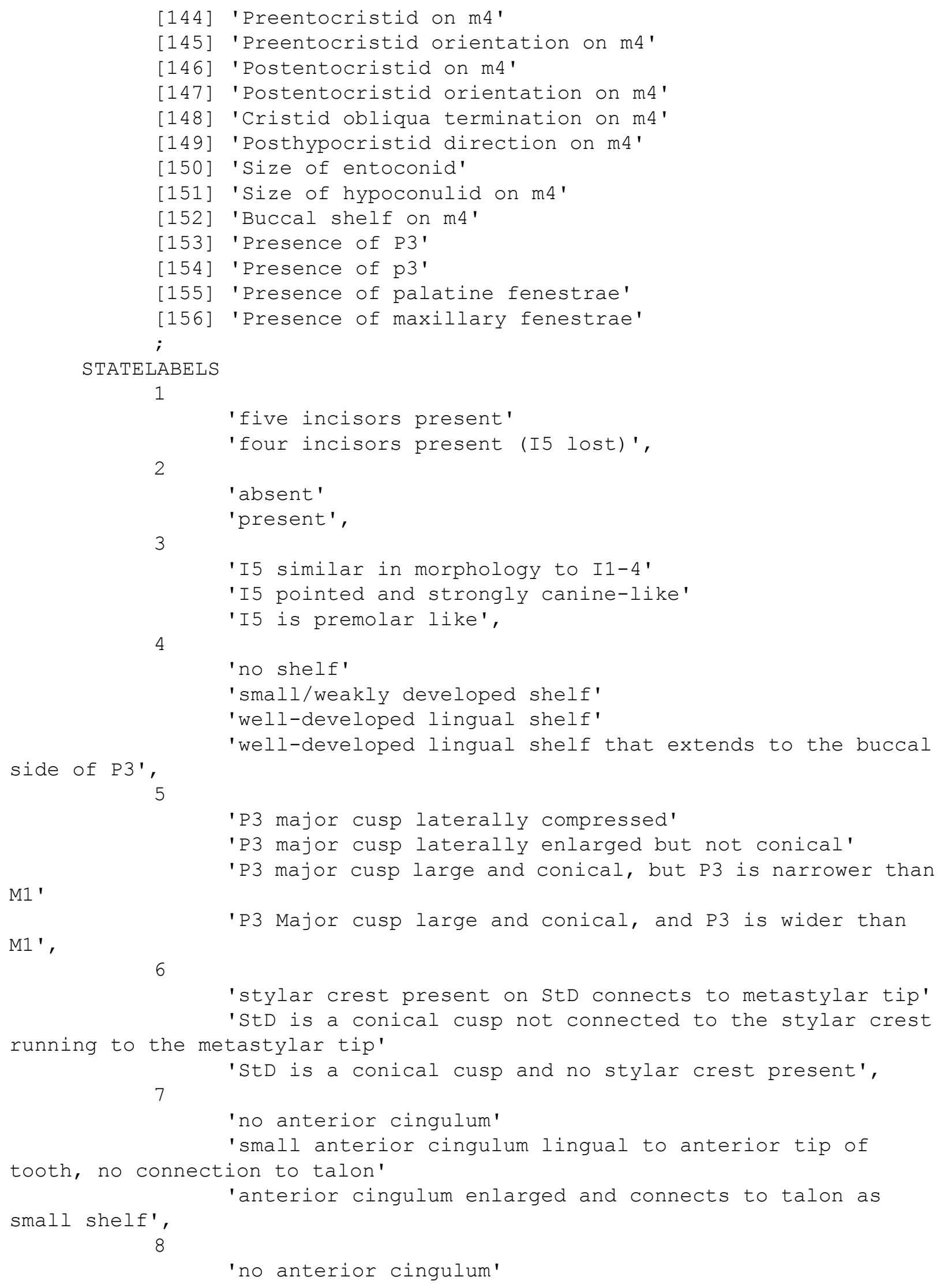




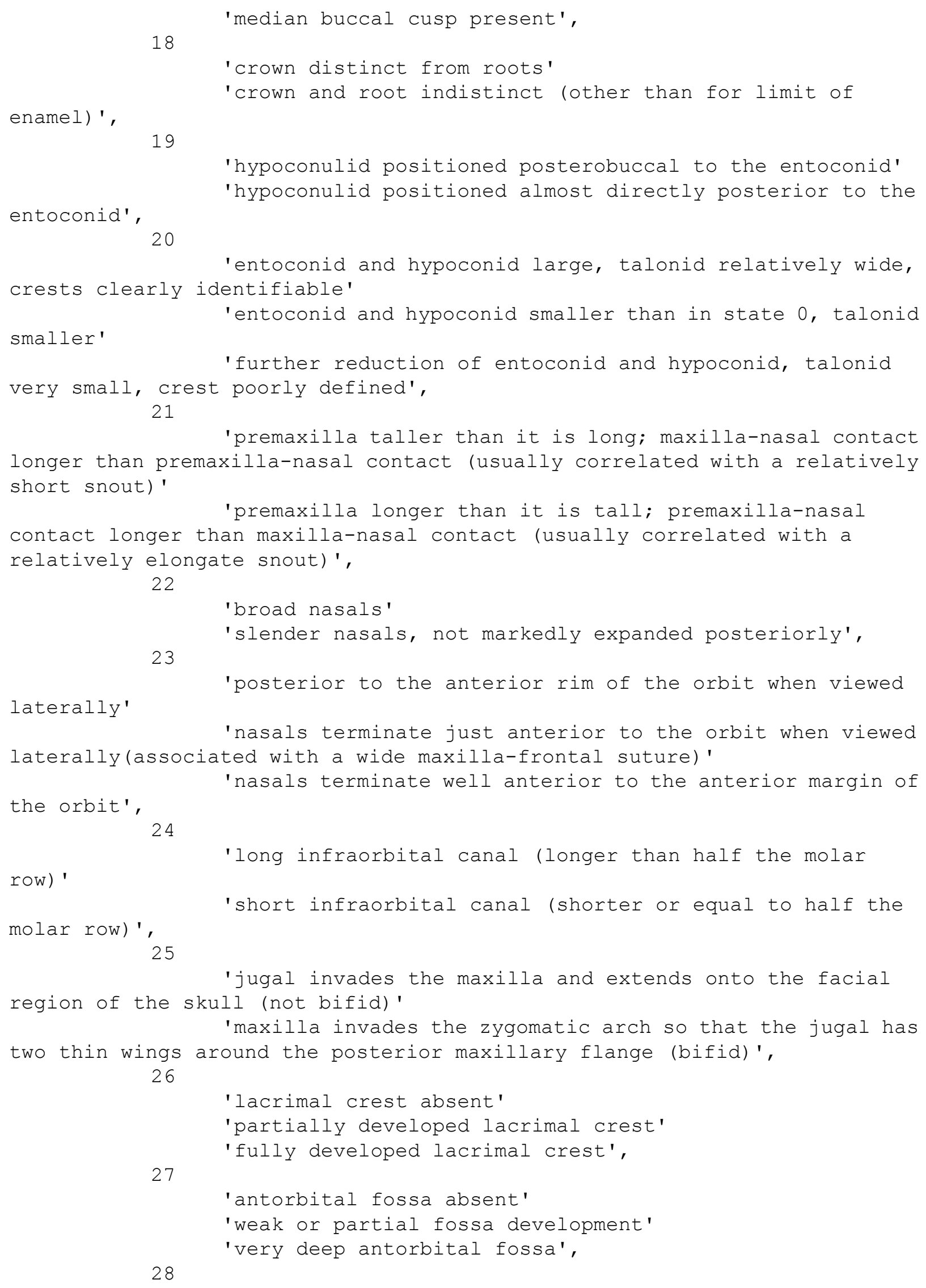




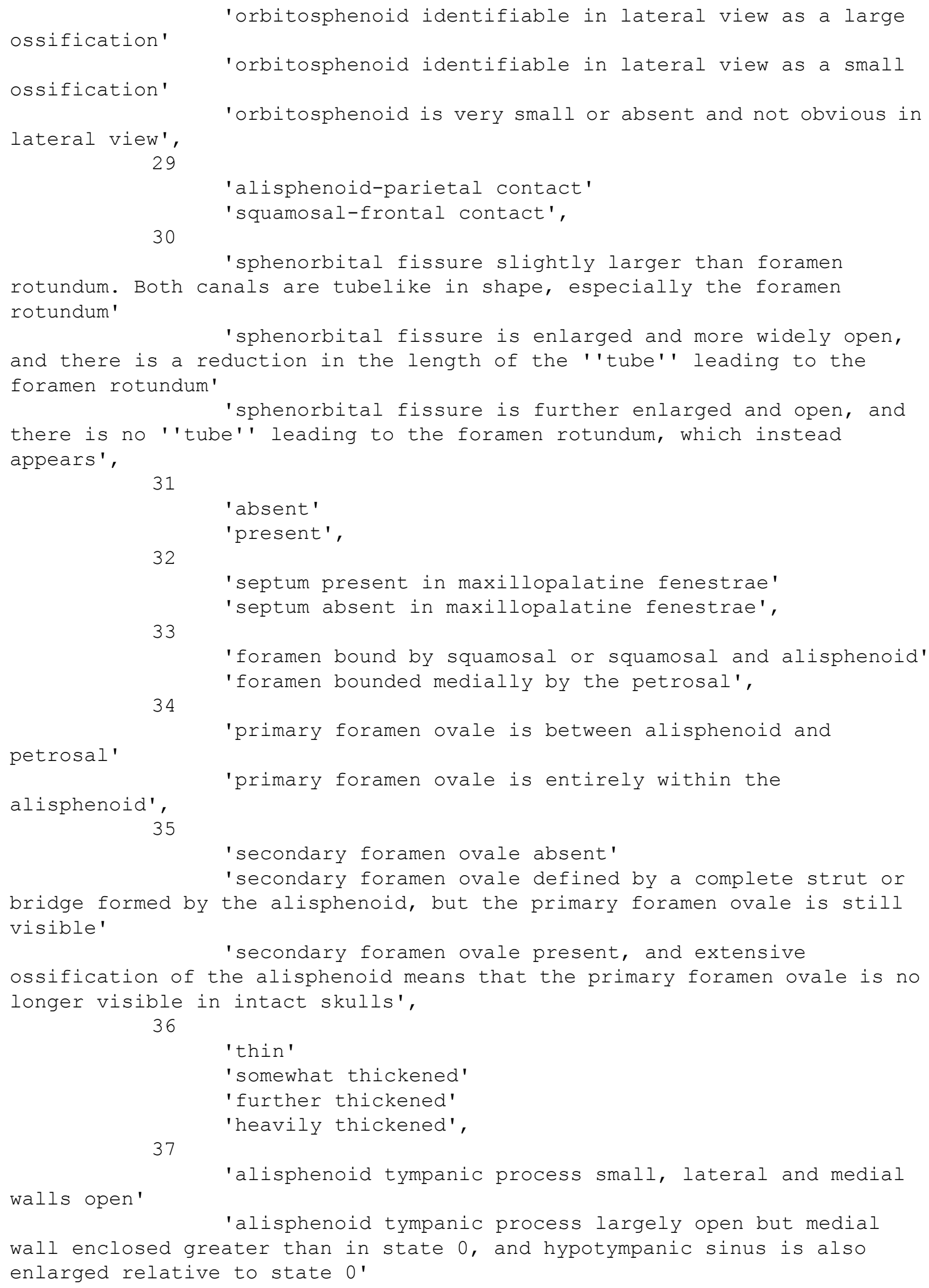

'alisphenoid tympanic process largely open but medial wall enclosed greater than in state 0, and hypotympanic sinus is also enlarged relative to state $0^{\prime}$ 
'alisphenoid tympanic process and hypotympanic sinus further enlarged.relative to state 1 ; hypotympanic sinus walled posteriorly by the alisphenoid'

'alisphenoid tympanic process and hypotympanic sinus greatly hypertrophied',

38

'flattened'

'ventrally rounded, anterior boundary rounded does not extend as far as the transverse foramen or foramen ovale'

'ventrally rounded, anterior boundary pointed and extends as far as the transverse foramen'

'ventrally angular, anterior boundary pointed and terminates anterior to the transverse foramen', 39

small'

'rostral tympanic process of the petrosal absent or very

'rostral tympanic process of the petrosal forms a distinct projecting process that partially walls the posteromedial margin of the hypotympanic sinus'

'rostral tympanic process of the petrosal further enlarged, forming elongate crestlike process that extends the length of the promontorium and forms posteromedial wall of the hypotympanic sinus; medial margin of petrosal overlaps basioccipital'

'ventral margin of the rostral tympanic process of the petrosal extends laterally and slightly dorsally, resulting in the formation of a distinct hypotympanic sinus within the rostral tympanic process itself'

'further dorsal extention of the ventral margin of the rostral tympanic process relative to state 3, resulting in lateral wall to the hypotympanic sinus within the process',

40

'poorly defined and shallow'

'wider and deeper than the plesiomorphic state but still relatively poorly defined'

'deep sinus with enclosing walls that is well

distinguished from remainder of auditory cavity'

'wide and deep sinus that extends posterolaterally',

41

42

'absent'

'present, poorly defined'

'wide with high posterior wall'

'deep and round',

'supraoccipital about as tall as it is wide'

'supraoccipital taller than it is wide',

44

'absent or indistinct'

'present',

'median suture present'

'partially or completely co-ossified suture', 
46

47

48

49

50

51

52

53

54

55

56

57

58

59

supraoccipital 'no sagittal crest'

'sagittal crest small, not extending to frontals'

'sagittal crest large and extending to frontals',

'absent'

'present',

'absent'

'present',

'one mental foramen'

'two mental foramina'

'three or more mental foramina',

'styliform or chisel-like'

'mesiodistally expanded and flat-crowned',

'occupies premaxillary-maxillary suture'

'entirely contained within maxillary',

'P2 taller than P3'

'P2 and P3 subequal in height'

'P3 taller than P2',

'well-developed posterior cutting edge'

'lacking posterior cutting edge',

'p2 taller than p3'

'p2 and p3 subequal in height'

'p3 taller than p2',

'present in anterior cingulum of m2-4'

'absent',

'buccally salient to protoconid'

'subequal to protoconid'

'lingual to salient protoconid',

'absent'

'present',

'no distinct process'

'''wing-like'' narial processes present',

'within lacrimal'

'within lacrimal-maxillary suture',

'contributes to superior margin of foramen magnum'

'exoccipitals contact each other medially, excluding the 60 


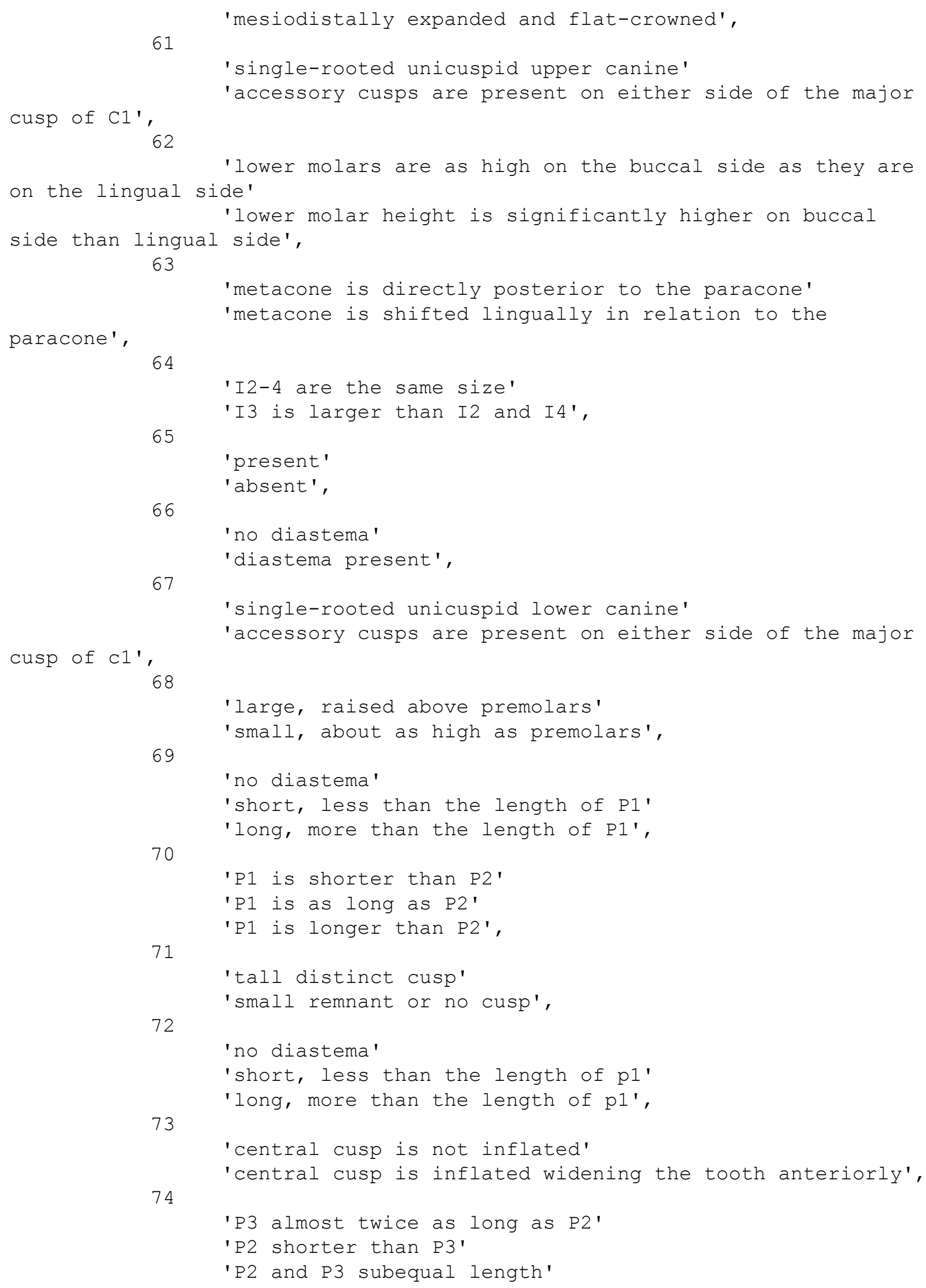




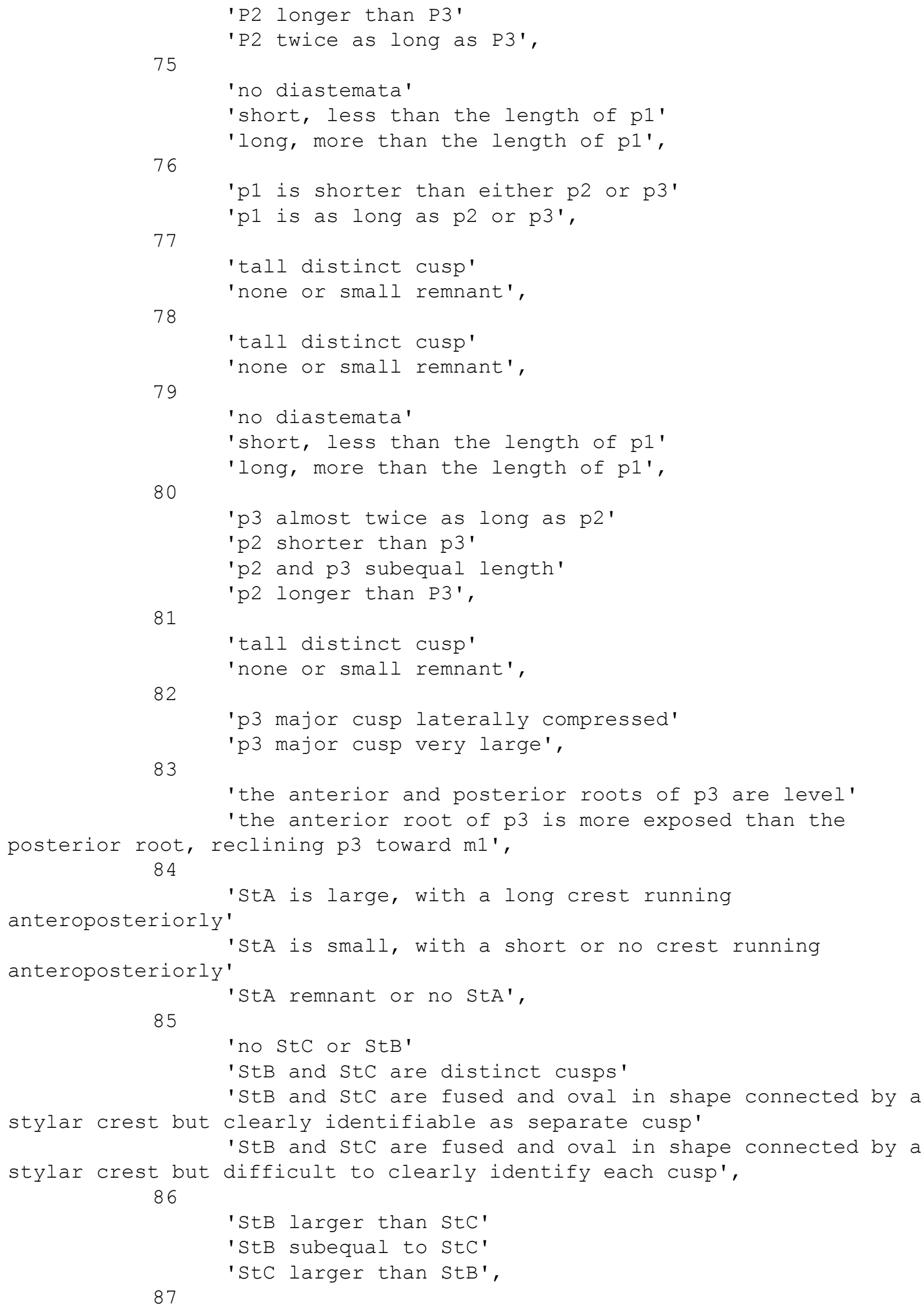




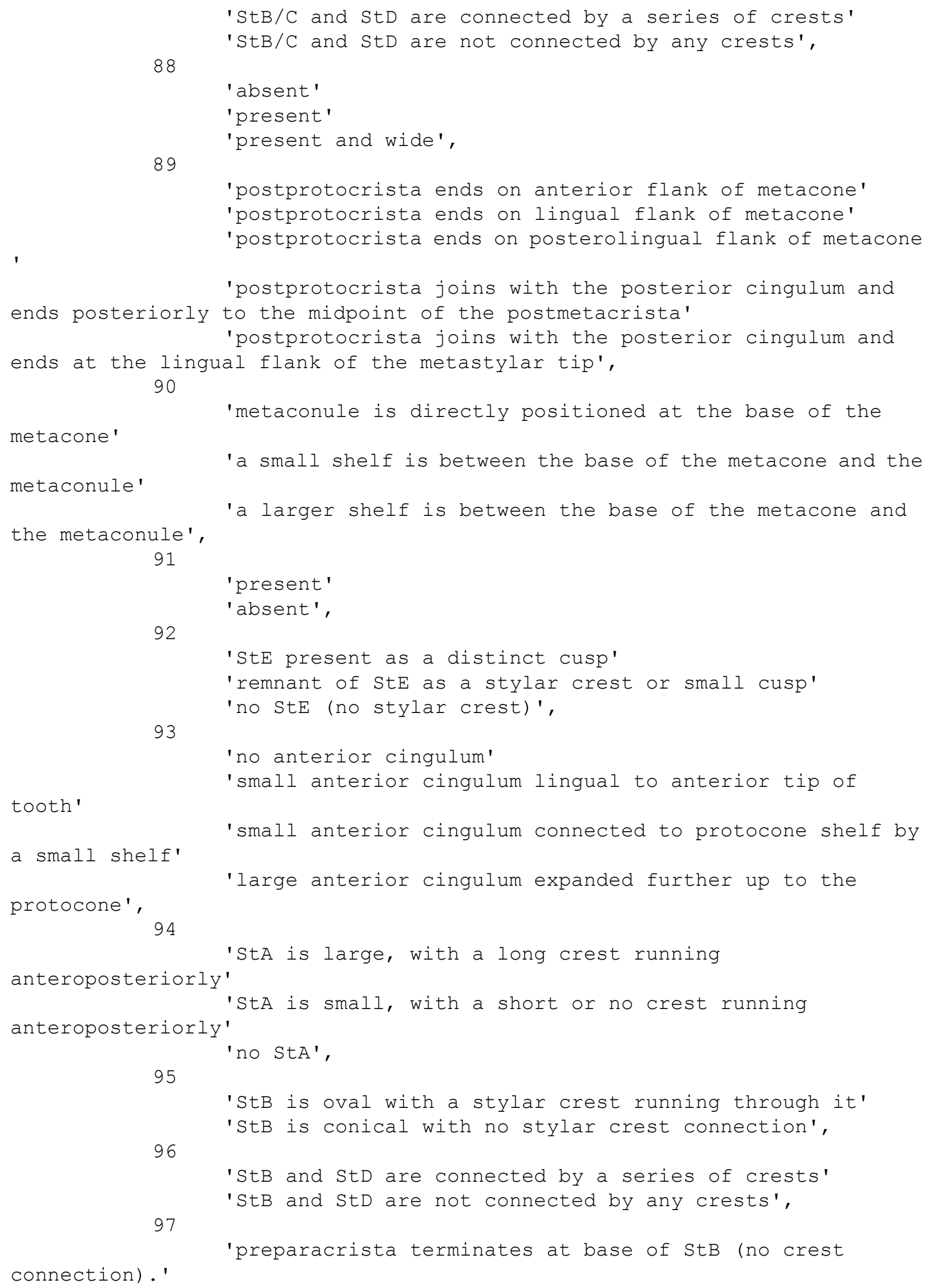




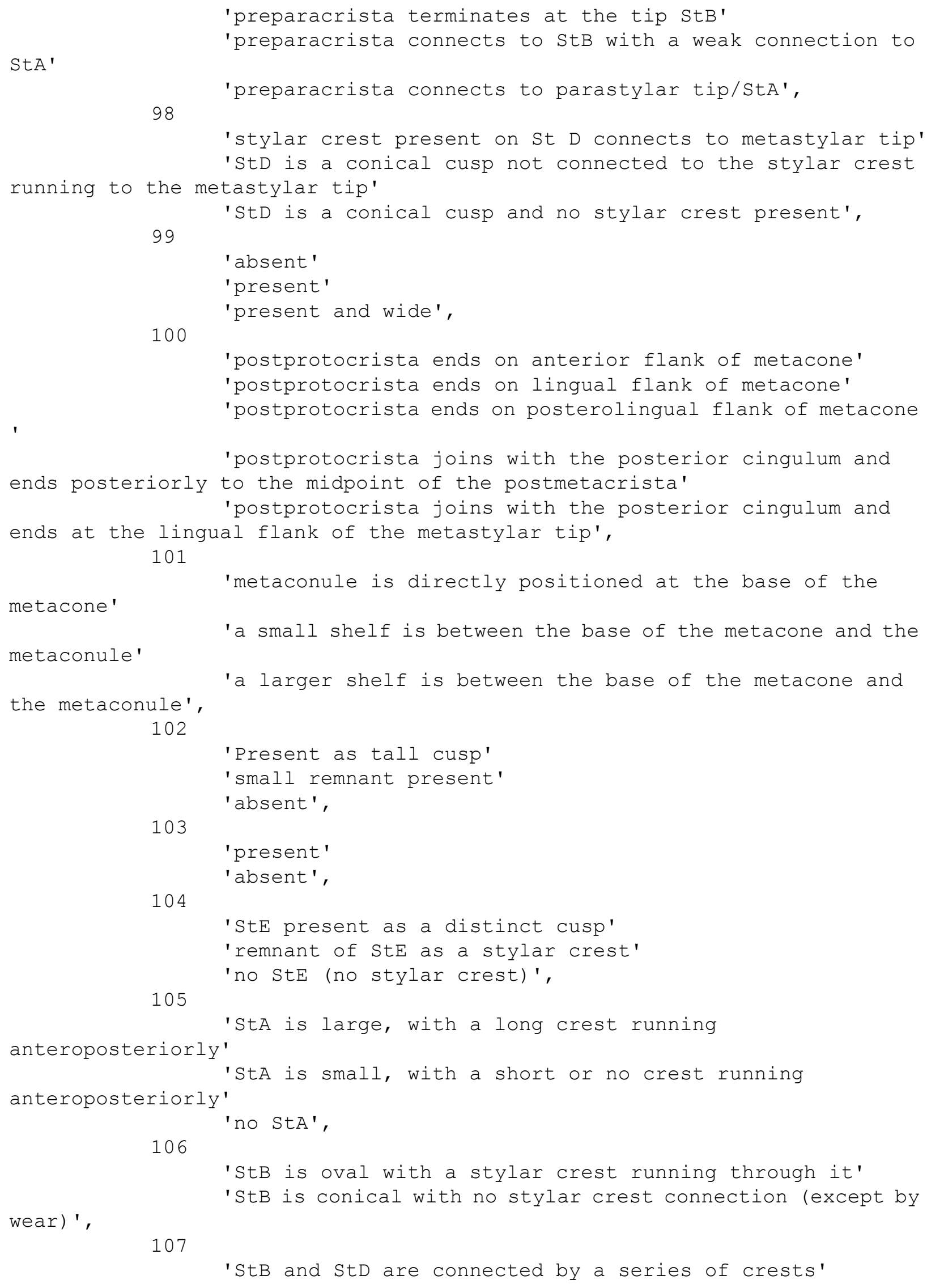


TRAVOUILLON ET AL: OLIGOCENE BANDICOOT

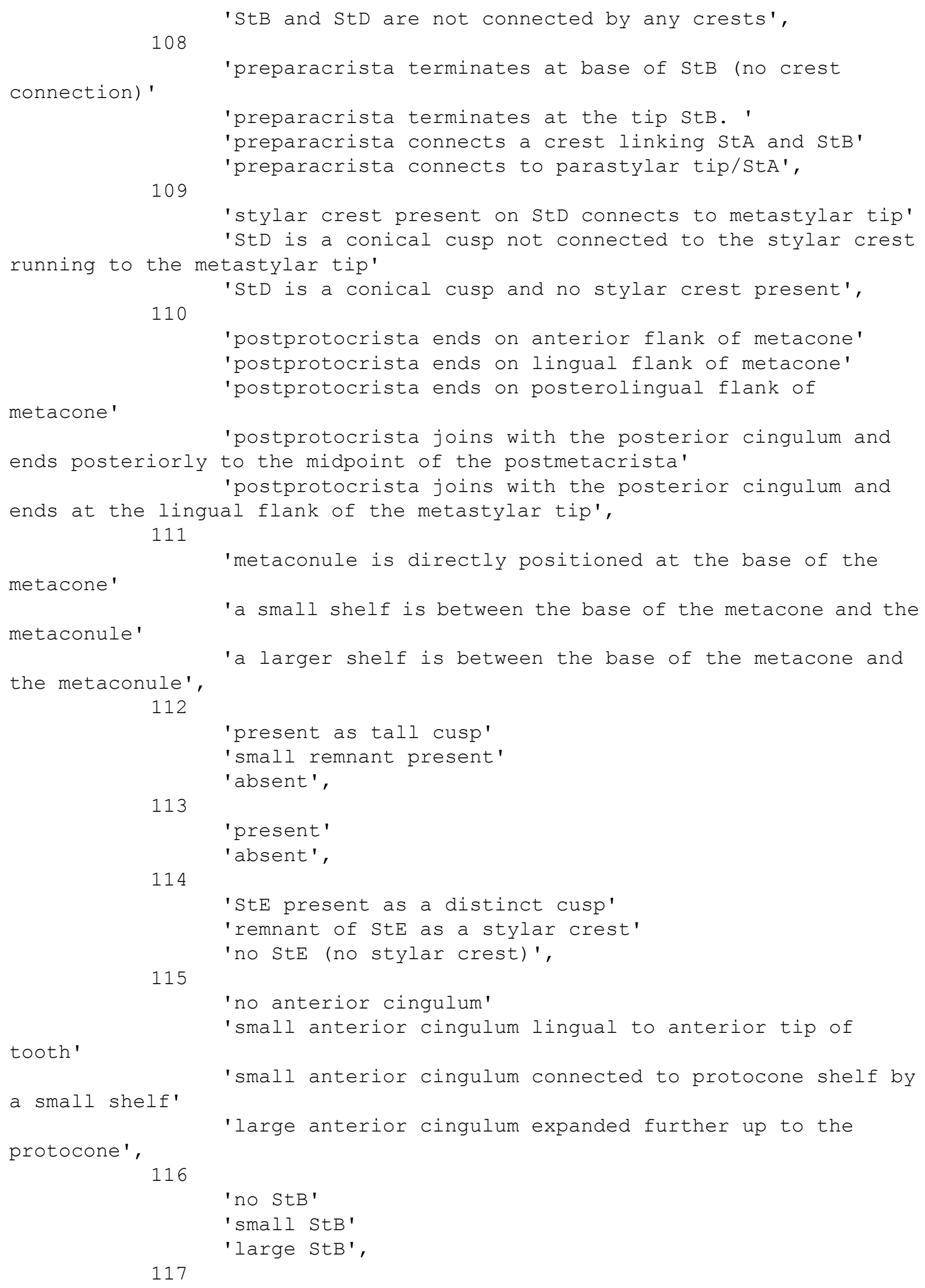




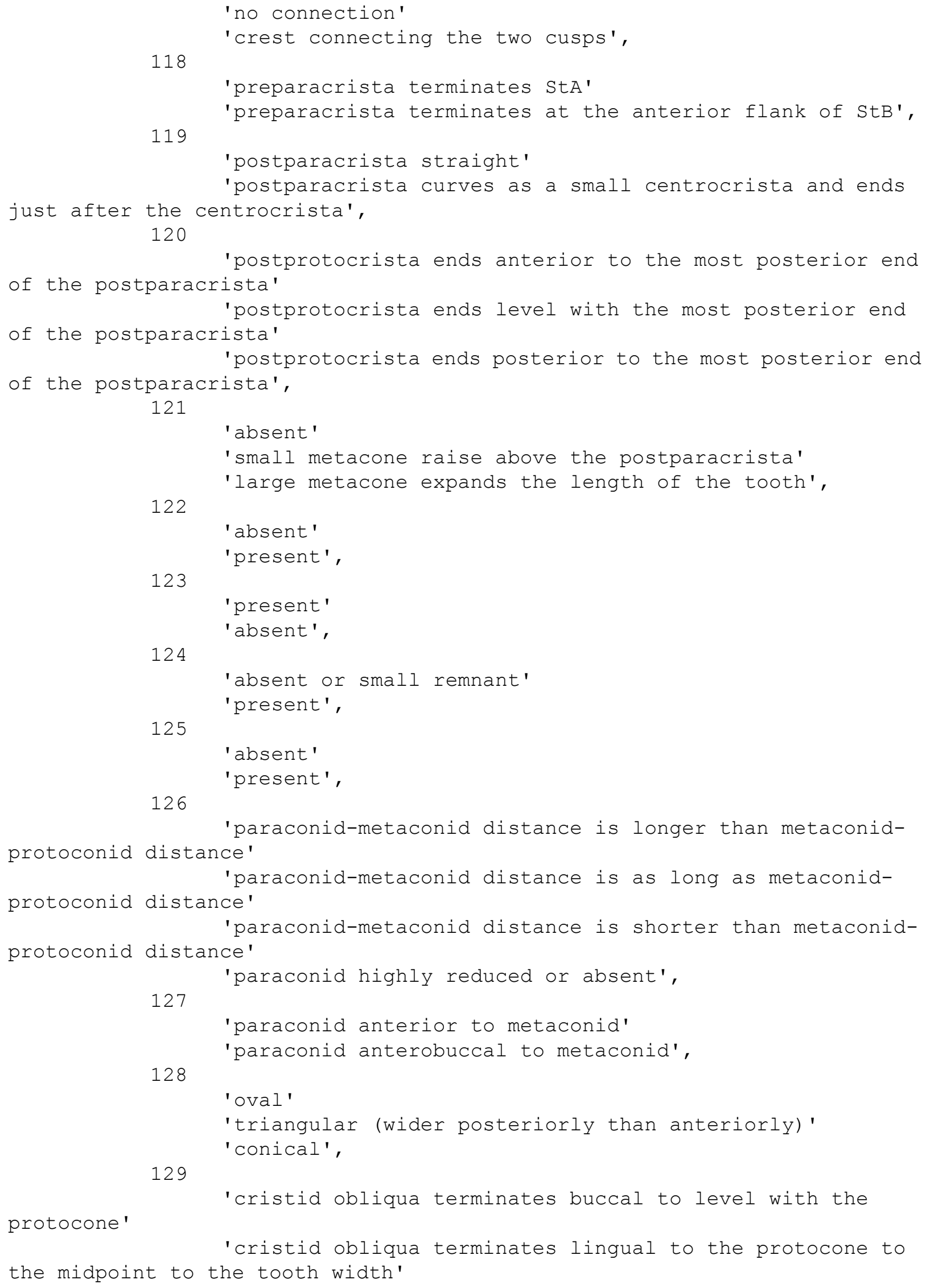




\section{TRAVOUILLON ET AL: OLIGOCENE BANDICOOT}

the tooth width',

'cristid obliqua terminates lingual to the midpoint of 130

131

'oblique to the tooth row axis'

'perpendicular to the tooth row axis',

'posthypocristid connects to hypoconulid'

'posthypocristid connects to base of entoconid when the tooth is unworn, but as the tooth wears down, a crest connects the tip of the entoconid to the posthypocristid', 132

'large distinct cusp'

'small cusp', protoconid distance'

'paraconid-metaconid distance is longer than metaconidprotoconid distance'

'paraconid-metaconid distance is as long as metaconid-

'paraconid-metaconid distance is shorter than metaconidprotoconid distance'

'paraconid highly reduced or absent',

134

'cristid obliqua terminates buccal to the protocone'

'cristid obliqua terminates lingual to the protocone

about midpoint to the tooth width'

'cristid obliqua terminates lingual to the midpoint of the tooth width',

135

136

'oblique to the tooth row axis'

'perpendicular to the tooth row axisp ',

'posthypocristid connects to hypoconulid'

'posthypocristid connects to entoconid',

137

'large distinct cusp'

'small cusp'

138

'hypoconulid absent',

protoconid distance'

'paraconid-metaconid distance is longer than metaconidprotoconid distance'

'paraconid-metaconid distance is as longer as metaconidprotoconid distance'

'paraconid-metaconid distance is shorter than metaconid139

'paraconid highly reduced or absent',

about midpoint to the tooth width'

'cristid obliqua terminates buccal to the protocone'

'cristid obliqua terminates lingual to the protocone

'cristid obliqua terminates lingual to the midpoint of the tooth width', 
141

'oblique to the tooth row axis'

'perpendicular to the tooth row axis',

'posthypocristid connects to hypoconulid'

'posthypocristid connects to entoconid',

142

143

'large distinct cusp'

'small cusp'

'hypoconulid absent',

'paraconid-metaconid distance is longer than metaconidprotoconid distance'

'paraconid-metaconid distance is as longer as metaconidprotoconid distance'

'paraconid-metaconid distance is shorter than metaconidprotoconid distance'

'paraconid highly reduced or absent',

144

145

'present'

'absent',

'anteroposterior'

'oblique',

146

'absent'

'present',

147

148

'anteroposterior'

'oblique',

'cristid obliqua terminates lingual to the protocone about midpoint to the tooth width'

'cristid obliqua terminates lingual to the midpoint of the tooth width',

'oblique to the tooth row axis'

'perpendicular to the tooth row axis '

'anteriorly orientated',

150

'large distinct cusp'

'small cusp'

'entoconid absent',

151

'large distinct cusp'

'small cusp'

152

'hypoconulid absent',

'buccal shelf end at buccal side of hypoconid'

'buccal shelf buccally reduced (hypoconid more buccal

than shelf)',

153

'present' 


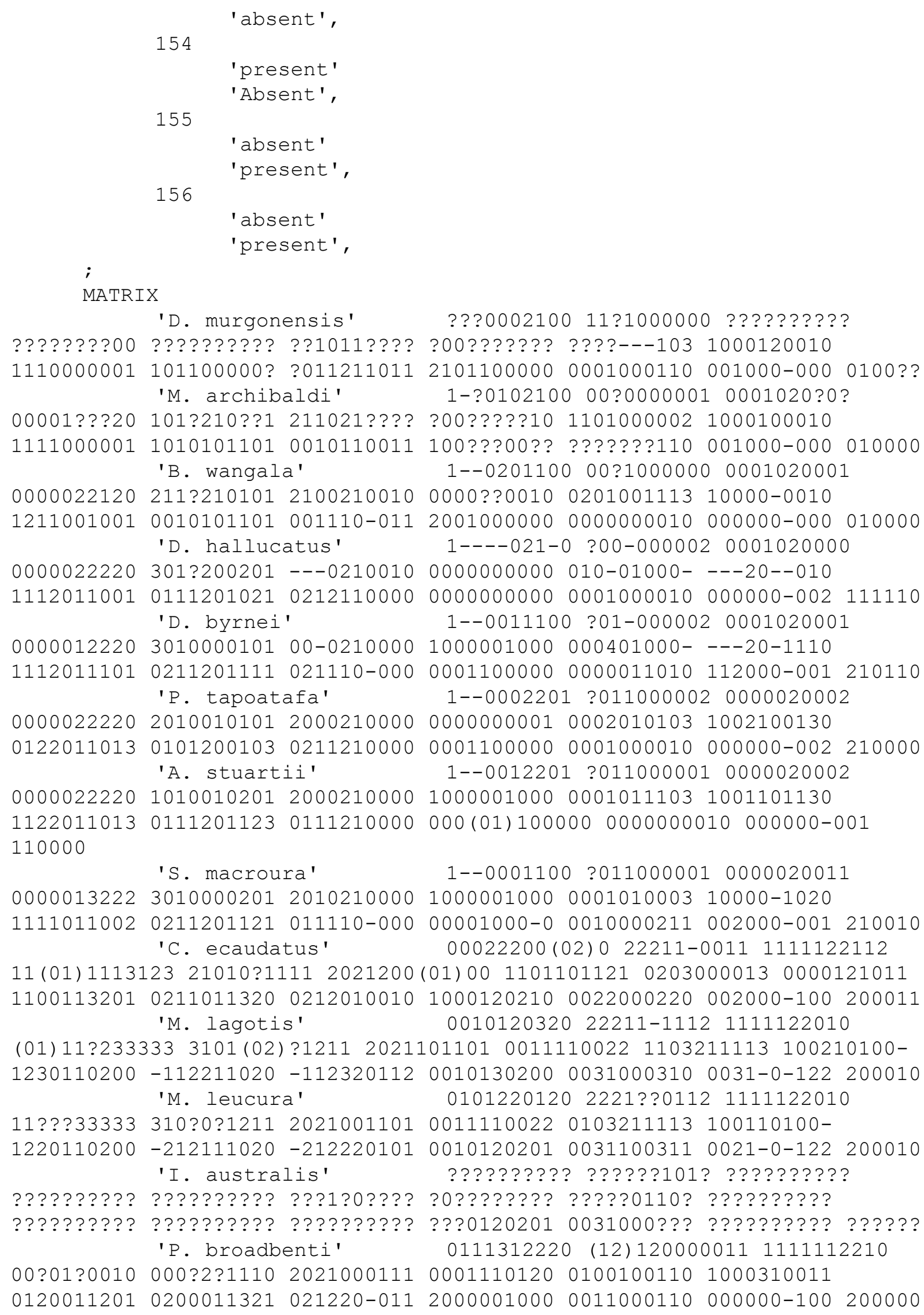


'P. raffrayana' 011210213022200000111110111210 001110000000010011101021000101000111012001011011110000311021 $011001200212010013211102111000000(01) 0000000021000211000000-100$ 200000

$$
\text { 'M.longicauda' } 011100013022200000121121111110
$$

100110001000010011111001101001100111012101012000131000311021

$011001210212110113211212010000100000000000110002110111-0-111200000$ 'M. papuensis' 011100013022210000121121111110

10????00?? ?00?0?1?11 2001101001 000111112102032000231000311010 $111011300112110113211212010010100000000000110002100011-0-110$ $2000(01) 0$

$$
\text { 'R. prattorum' 1--1202120 } 22200000111121101 \text { (12) } 11
$$

00?111111? $000(01) 0011112021001(01) 01 \quad 100111012001022010211000221021$

$002011320112020013211100010011200000000000110001100001-0-100100000$

$$
\text { 'E. Clara' } 1--1301130 ? 2200000121111112110
$$

00?1101010 010?(02)?1111 2021101011000111002012002010101100211010

$111001120112020012211102211011100000000001110011100101-0-101100000$

$$
\text { 'E. davidi' 1--1201130 } 2220000011 \text { 11?111111? }
$$

00???0??1? 0?0?0?1111 20210010?1 100111012002012011110100311021

011001120212000113221110210001100000011001110012100100010100200000

$$
\text { 'E. kalubu' } 1--210223022200000121111111110
$$

$0001(12) 0101001010011112021001001 \quad 100111012001022010110000221021$

$011001310211010113121000210011100001011000210002100101-0-101200000$

$$
\text { 'E. rufescens' } 1--111223022200000121111111210
$$

00??201010 010?0?1111 $2021001001 \quad 100111012002012010110000321021$

$011001300212010113221001(12) 10011210(01) 00010000210002100000111110$

100000

$$
\text { 'cf. P. tedfordi' ?????01120 22??00001? ?????????? }
$$

?????????? ?????????? ???100???? ?00??????? ?????????? 00?0321010

011001110111010113111211 ?????? ???0100010 0011000110 00???????? ?????? 'cf. P. sp.' ?????01?2? 2???00001? ??????????

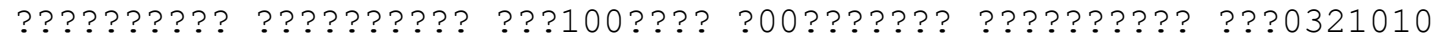

01??????? ?????????? ?????????? ???0100000 00 ?????211 10???????? ?????? 'I. auratus' 01122123122221 ??1111 1120121111

10 ??223242 310?0?1111 2021001001010111101101121100130101221242

$10201131242210011324221232001110001212110021100211012010-010200010$ 'I. obesulus' 011221231222200111111111121111

(01)0??223242 310?(01)?1111 $2021001001010111(01) 011011211001$ (23)

0101221242102011312422100113242212320011 (12)00(01)121211 0021100211

$112010-0102000(01) 0$

'I. macrourus' $01132223222220(01) 111111111121111$

(01)01?223242 $3101201111202100100101011110(12) 101111100110101221242$ $10201132242210011324221032001121001212010021100211112010-000$ $2000(01) 0$

'P. nasuta' $01121120212220 ? ? 10111120121212$

$01 ? 1112121$ 110?(01)?1211 $20210010010001111011010120001(23) 0000321232$

$010011311222(01) 001132222120100112(01) 0011020000211012111121-0-110$ $2100(01) 0$

'P. bougainville' 01111120202221 ??0012 1120122212

11 ??213121 210?0?1(12)11 2021001001000111102101022100130000221022 $110011310222110113212210010010100011020000211012110121-0-111200010$ 


\title{
TRAVOUILLON ET AL: OLIGOCENE BANDICOOT
}

\author{
'P. gunnii' \\ $012222202022211-00111120122212$ \\ $111111312111010011112021001001 \quad 100111102101022000120000221022$ \\ $120001320222(01) 00113212210020000210011020010211102111021-0-100$ \\ 210010 \\ 'P. eremiana' 01?1112030 2221??0012 1120122212 \\ $10 ? 1113121 \quad 110 ? 0 ? 11112021001001000111 ? 02102022100130000211022$ \\ $110011310222110113212212010010100011020000211012110121-0-11$ ? 200010 \\ 'P. sobbei' \\ ???????0?0 22?0??0012 ??????????

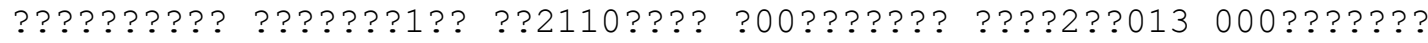 \\ ??10113102 ?211011321 0212?????? ??0110201 1121111211 1121-0-111 20?0?? \\ 'P. bowensis' ???22??1?0 22??01001? ??????????

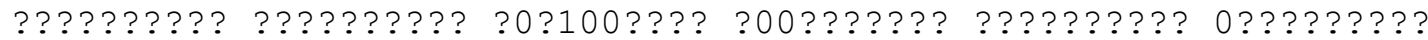 \\ ??10113202 221?011321 0212?????? ???0100210 00?????211 11???????? ?????? \\ 'P. allinghamensis' ?????????? 2????????? ?????????? \\ ????????? ????????? ????????? ??0?????? ????????? ????????? \\ ??20113202 221 ?????? ????????? ????????? ????????? ?????????? ?????? \\ 'Y. burchfieldi' ???1002120 11201-0012 ?100111000 \\ 1?100???21 000?2?11?1 ?02120?10? 000?1000?? ????001002 1010320010 \\ $11100030010111000311021110-00000011002000000000010$ 0011-0-112 200000 \\ 'Y. kida' \\ ?????02120 11??000012 ?????????? \\ ????????? ????????? ???120??? ?00?????? ????????? ???0321010 \\ 11100030010111000321021111000000011000000000000010 0011-0-112 20???? \\ 'G. speciosus' $00 ? 1202210$ (12)2?0000011 0101111000 \\ 00100???11 100?2?11?1 202100000? 000???0000 0101001101 1110310131 \\ $11200030021211010322121121000000001000100011000210002000-110200000$ \\ 'G. grandis' \\ ?????02201 11 ??000011 ?????????? \\ ????????? ??????,1?? ??2110???? ?00???00?? ????101111 1110320131 \\ 112000301312110003221201 ????? ???0100010 0011000110 000000-100 10?0?? \\ 'G. amplus' \\ ???1202210 22??000011 ?101111??? \\ 10??????? ??0?2??1?1 ?02100?0?? 000???0010 ?2??101111 1110320131 \\ $11200130021211011322121020-000000111101000211002110021-0-110200000$ \\ 'G. adversus' \\ ?????02210 21???????? ???11?1??? \\ ????????? ????????? ????????? ?00?????? ????????? ???0310110 \\ 112001301102110113210211210000 000?????? ????????? ????????? ?????? \\ 'B. palara' ???1001120 (12)221000011 ?1001?1000 \\ 10?00?1121 100?0?1(12)?? 2021(01)0??0? 0?0?1000?0 1101101003 00102(02)0011 \\ $011000(13) 001110100132111121(01) 0000100(01) 100(01) 000021000211$ \\ (01) 01000-010 200000 \\ 'B. muirheadae' \\ ?????01110 11??000011 ?????????? \\ ????????? ????????? ???100???? ??0?????? ????????? ???0221010 \\ 011001000101010013110110 ????? ???1100000 00200002110010010000 10???? \\ 'B. campbelli' \\ ???????1?0 ?2??000011 ?????????? \\ ????????? ????????? ???100??? ??0?????? ????????? ????????? \\ ????????? ????001321 111?????? ???11?0(01)00 0?21000211 0010010100 \\ 10 ? ?? \\ ENDBLOCK; \\ BEGIN ASSUMPTIONS; \\ OPTIONS DEFTYPE=UNORD POLYTCOUNT=MINSTEPS; \\ TYPESET * default = ORD: $4-13202326-283035-3739454851$ \\ $535569-7274-7579-80848688-9092-9497-102104-105108$ \\ - $112114-116120-121126129133-134137-139142-143149$ - 151;
}


PALAEO-ELECTRONICA.ORG

ENDBLOCK; 


\section{APPENDIX 3}

Topology enforced in our molecular scaffold analysis (based on Krajewski et al., 2007; Westerman et al., 2008, 2012):

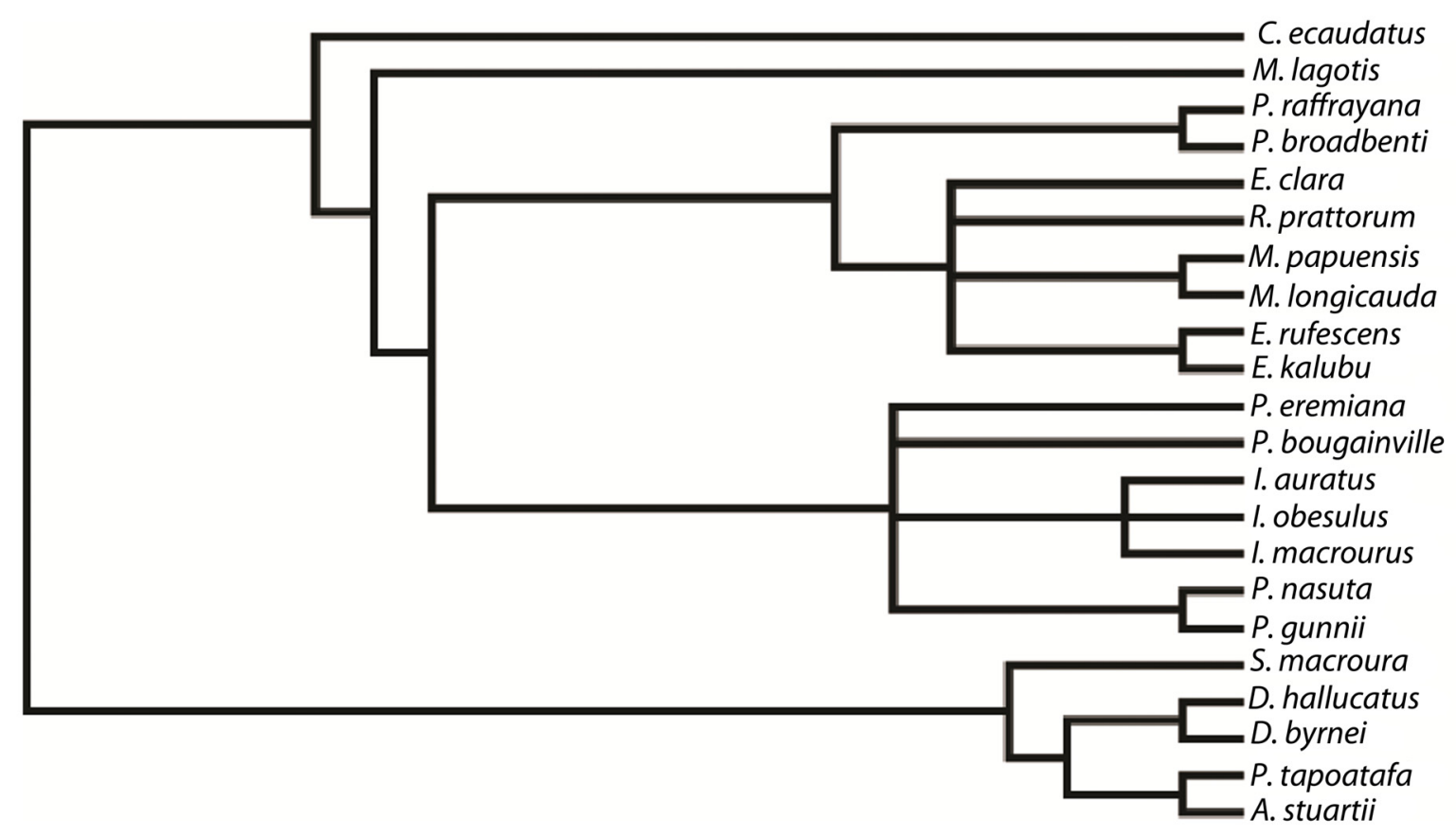

